\title{
EL YACIMIENTO DE LA ESTACIÓN DE LAS DELICIAS (MADRID) Y LA INVESTIGACIÓN DEL PALEOLÍTICO EN EL MANZANARES
}

\section{THE ESTACIÓN DE LAS DELICIAS SITE (MADRID) AND PALEOLITHIC RESEARCH IN THE MANZANARES VALLEY}

\author{
por \\ M. SANTONJA ${ }^{1}$, \\ A. PÉREZ-GONZÁLEZ ${ }^{2}$ y \\ G. VEGA TOSCANO ${ }^{3}$
}

RESUMEN

\begin{abstract}
El yacimiento madrileño de las Delicias, excavado por Obermaier y Wernert en 1918, ha sido durante décadas uno de los más notables del conjunto de localidades paleolíticas clásicas del valle del Manzanares. En el presente artículo se hace un repaso crítico de la documentación ofrecida por la antigua excavación, se evalúan historiográficamente las distintas interpretaciones vertidas sobre la industria del yacimiento y se enumeran algunos de los objetivos sobre los que construir un nuevo proyecto de excavación sobre los depósitos aún conservados del mismo.
\end{abstract}

\begin{abstract}
The archaeological site of Las Delicias (Madrid) excavated by Obermaier and Wernert in 1918, it has been one of the most important classic palaeolithic sites of the Manzanares valley for years. In this paper we offer a critical review of all the data caming from ancient excavation, together with an historiographical evaluation of the different interpretations based on lithic industry of the site, and finally we want to set some objectives looking for a new archaeological research in the Delicia's remaining sediments.
\end{abstract}

Palabras claves Paleolítico, valle del Manzanares, Las Delicias, historia de la investigación, terrazas fluviales.

Key words Paleolithic, Manzanares valley, Las Delicias, research history, river terraces

1. Museo de Salamanca.musal@helcom.es

2. Departamento de Geodinámica. Universidad Complutense. alfredog@eucmax.sim.ucm.es

3. Departamento de Prehistoria. Universidad Complutense. toscano@eucmax.sim.ucm.es 
La excavación que Obermaier y Wernert realizaron a finales de 1917 en la estación de ferrocarril de Las Delicias, entonces en las afueras de Madrid y hoy en pleno casco urbano (Fig. 1), permitió la obtención en niveles de sedimentos finos de un conjunto industrial amplio, significativo y aparentemente bien conservado (Obermaier y Wernert 1918). Aunque no existía fauna, Las Delicias se reveló desde su descubrimiento como un yacimiento notable y prueba de ello es que ha conseguido mantener cierto interés incluso entre los investigadores actuales.

Sorprendentemente, la topografía del área en torno al yacimiento ha subsistido con escasas modificaciones desde 1918. Se ha arruinado el almacén de la estación de ferrocarril cuya construcción determinó la excavación, pero los terraplenes inmediatos permanecen en un estado muy parecido (Lam. I), por lo que, en nuestra opinión y tras una evaluación somera del entorno, resultaría posible volver a excavar en zonas aún fértiles del yacimiento original, ya que subsisten depósitos intactos.

Desde esta perspectiva y con la intención de establecer el alcance de la información disponible, analizaremos en las siguientes páginas la historiografía de esta singular localidad y las incógnitas que sigue planteando. Creemos que, además, es una buena oportunidad para ofrecer ciertas reflexiones sobre algunos trabajos realizados acerca del Paleolítico del Manzanares, centrándonos en la incidencia que han tenido en la valoración actual de Las Delicias. Queremos finalmente plantear nuevas hipótesis alternativas en relación con su significado cultural y funcional, e intentar definir los objetivos de un nuevo proyecto de investigación en este enclave clásico del Pleistoceno madrileño.

\section{I.- LA INVESTIGACIÓN DEL PALEOLÍTICO DEL MANZANARES}

\section{1/ Conocimientos anteriores al descubrimiento de Las Delicias}

Como es bien conocido, la Prehistoria española empieza cuando Casiano de Prado (1787-1866), ingeniero, activista político y hombre de ciencia ciertamente notable (Sequeiros 1996), recogía en 1850 un par de fragmentos de sílex con formas insólitas procedentes de los depósitos fluviales de la localidad de San Isidro del Campo, junto a la popular ermita del santo madrileño. Según su propia confesión (de Prado 1864), solo comprendió el verdadero significado de este tipo de restos varios años después, exactamente en la primavera de 1862, cuando volvió a visitar las graveras de San Isidro acompañado por Philippe Edouard Poulletier de Verneuil (1805-1873) y Louis Lartet (1840-1899) -hijo del célebre Eduard Lartet (1801-1871), uno de los pioneros en los estudios prehistóricos de la Francia de mediados del s. XIX, quienes identificaron al menos una pieza como fruto inequívoco de la mano del hombre. Este útil (tal vez un hendedor, según los dibujos) fue publicado por ambos al año siguiente, a su regreso a Francia, y reproducido por Casiano de Prado junto a otra media docena recuperados por él mismo, todos ellos procedentes de los aluviones de San Isidro (de Prado 1864; Ayarzagüena 1997).

Estos inicios parecían augurar un futuro brillante para las investigaciones prehistóricas en el valle del Manzanares; pero las expectativas no se cumplieron en absoluto. Medio siglo después, al estallar la I Guerra Mundial, la situación era casi la misma que cuando de Prado publicara su célebre descubrimiento, sencillamente porque falleció en 1866 y nadie continuó sus trabajos de campo. Al contrario de lo que ocurrió durante esas décadas en otros países, sobre todo en Francia, donde se desarrollaron proyectos de investigación sistemáticos encaminados a determinar las grandes fases en el desarrollo del Paleolítico, según los principios evolucionistas dominantes (Groenen 1994), en nuestro país las principales figuras de la época se ocuparon más de la divulgación que de la verdadera investigación en el campo de la Prehistoria, como fue el caso de J. Vilanova (Maier 2000: 59), quién en cierto modo debería haber sido el continuador de la labor de Casiano de Prado en Madrid. 
Sería injusto, sin embargo, no reconocer que en las décadas finales del XIX los descubrimientos realizados en el Cerro de San Isidro llamaban la atención; pero ese interés sólo se plasmó en artículos esporádicos que comentaban breves excursiones académicas y cuyo contenido aportaba más confusión que otra cosa al conocimiento del importante yacimiento (Wernert y Pérez de Barradas 1925; Obermaier 1925; Maier 2000). De esta época proceden también algunos conjuntos de piezas líticas, como la colección Quiroga o la colección Rotondo, ambos discípulos de J. Vilanova, que pasaron después a integrar los fondos del Museo de Ciencias Naturales y del Museo Arqueológico Nacional, en teoría con materiales procedentes de San Isidro, pero cuyo verdadero origen es dudoso, al menos en parte, como hace bastante tiempo llegó a señalarse (Royo et al. 1929: 85).

Al empezar la I Guerra Mundial el Profesor Hugo Obermaier (1877-1946) y su ayudante, Paul Wernert (1889-1972), ambos súbditos alemanes, excavaban bajo el patrocinio del Institut de Paléontologie Humaine de París en la Cueva del Castillo. La deflagración del conflicto europeo les llevó a permanecer en España, siendo admitidos en el seno de la Comisión de Investigaciones Paleontológicas y Prehistóricas (Moure 1996), por lo que desde 1914 se establecieron en Madrid. Como hemos visto, por esas fechas San Isidro era un yacimiento célebre, divulgado por ilustres visitantes, pero su conocimiento real era claramente insatisfactorio, incluso para los cánones de la época. Las referencias más completas seguían siendo las publicadas por C. de Prado (1864) y M. de la Paz Graells (1897), y poco o nada se sabía del resto del valle del Manzanares. Obermaier, con la colaboración de Wernert y al amparo de la C.I.P.P. - presidida por el Marqués de Cerralbo, y en la que estaban integrados los cuaternaristas españoles más destacados, como E. Hernández Pacheco o el Conde de la Vega del Sella-, retomó por lo tanto unos estudios que apenas si habían despegado antes (Díaz-Andreu 1997). En 1916 excavaban en el barrio de Las Carolinas, en la terraza baja del Manzanares, registrando industrias del Paleolítico Superior y calcolíticas (Obermaier y Wernert 1917) y poco después, en diciembre de 1917, en Las Delicias, un yacimiento de mucha más entidad, y que en consecuencia fue objeto de una investigación más atenta. De hecho, la publicación de Obermaier y Wernert (1918) es probablemente uno de los trabajos con más interés sobre el Paleolítico del Manzanares de la etapa anterior a la Guerra Civil.

\section{2/ El estudio de Las Delicias por Obermaier y Wernert}

\section{Excavación y estratigrafía}

El yacimiento había sido reconocido en diciembre 1917 por Alejandro Guinea, un ingeniero de ferrocarriles, el mismo que en 1911 había descubierto el de Las Carolinas. Se encontraba en las inmediaciones de la estación de Las Delicias -actual sede del Museo del Ferrocarril-, $50 \mathrm{~m}$ al E.N.E. del edificio principal (fig. 2), a $590 \mathrm{~m}$ de altitud y 20-25 m por encima del Manzanares, del que dista poco más de un kilómetro.

Al construirse un almacén en ese punto, Guinea observó la gran abundancia de sílex tallados, y recogió una parte de ellos, comunicando a Obermaier el hallazgo. Éste, junto a Wernert, pudo aún excavar directamente unos $25 \mathrm{~m}^{2}$ en la parte N.O. del solar (fig. 2), identificando la zona con restos. El yacimiento se interrumpía hacia el S.S.E. y el N.N.O., mientras que por el O.S.O. no se conservaba el límite, pues tiempo atrás, al construirse la Estación, habría quedado parcialmente destruido. Lo más importante es que parecía claro que el nivel arqueológico continuaba en dirección E.N.E. (fig. 2). La superficie total observada, sumando la intervención de Guinea y la excavación, era de unos $72 \mathrm{~m}^{2}$. En ella se describió la siguiente estratigrafía (fig. 3): 
a) Tierra vegetal, 1,20 m de espesor máximo

b) Arcilla de color oscuro con concreciones caolínicas blancuzcas. 1,5 m

c) Capa arenosa de 5 a $8 \mathrm{~cm}$ Sólo aparecía en la zona ocupada por el edificio, no en el sector excavado.

d) Arcilla del Terciario.

Existía industria dispersa por el nivel a y por todo el b, pero la densidad se elevaba sobre todo en la base de éste, en una potencia de 10-15 cm (26 cm como máximo), de manera que en ese punto el "suelo" parecía "empedrado". La concentración reposaba directamente sobre las arcillas terciarias, y también continuaba en la capa arenosa c (Obermaier y Wernert 1918: 16). No se llegó a registrar nada de fauna.

Obermaier y Wernert consideraban que la actividad humana que originó una acumulación de sílex tan espectacular se había desarrollado directamente sobre la superficie terciaria, llegando después los sedimentos de los niveles b y c a recubrir y fosilizar los restos ${ }^{1}$.

\section{La primera interpretación de Las Delicias}

Un primer aspecto que llamó la atención de los prehistoriadores germanos fue la abundancia de sílex, ya que los afloramientos más próximos estaban en Cerro Negro y los relieves inmediatos a Vallecas y Vicálvaro y su existencia en Las Delicias sólo podía atribuirse a la actividad humana.

La presencia de sílex en los yacimientos del Manzanares hasta entonces conocidos, caso de San Isidro y Las Carolinas, más alejados aún de estratos geológicos con sílex, ya había sido subrayada anteriormente (Obermaier y Wernert 1917). Al mismo Casiano de Prado le llamó la atención en 1850 observar cantos de sílex "no rodados"en aluviones de San Isidro ${ }^{2}$, extrañeza que, como hemos visto, le movió a recoger alguno de ellos, aún antes de que se llegara a identificar algún artefacto en el Cerro (de Prado 1864). Royo y colbs., insistirían después en la misma opinión (1929: 121-122), precisando que en la parte occidental de la hoja geológica a e. 1:50.000 de Madrid, al N.O. de Cerro Negro, todo el sílex de los yacimientos podía tener un origen antrópico. Pérez de Barradas y Wernert se refirieron también en diversas ocasiones a esta circunstancia ${ }^{3}$, que paradójicamente en los últimos años ha sido poco valorada por los investigadores que se han ocupado de las materias primas en el Paleolítico del Manzanares.

La industria de Las Delicias no llegó a estudiarse de forma exhaustiva. Sin embargo, las observaciones que en su época se hicieron, aunque cualitativas, no carecen de interés. Una parte apreciable de la colección recuperada estaba formada por núcleos y productos de talla. Se mencionaron núcleos "discoideos" y "amigdaloides", así como otros más "toscos", entre los que se destacó especialmente un bloque de forma rectangular, de unos $30 \mathrm{~kg}$ de peso, que los excavadores supusieron que pudo ser empleado como "yunque", dada la cantidad de "sílex tallados" observada a su alrededor (Obermaier y Wernert 1918: 18-19). En algunas piezas reconocieron también fisuras de origen térmico (Ibídem: 17).

El estudio, como era costumbre entonces, se centró en la descripción de una selección de piezas, probablemente las únicas que fueron finalmente guardadas, las cuales actualmente se conservan, como veremos más adelante, en el Museo de Ciencias Naturales de Madrid. Resumiremos a continuación las conclusiones

1. "Durante la ocupación del yacimiento por los paleolíticos, fueron sin duda arrastradas por las lluvias, desde los alrededores más elevados, arenas, de las que forman la capa $c$ y las arcillas que forman la base del nivel $b$ " (Obermaier y Wernert 1918: 16).

2. Se trataba de piezas talladas, como el mismo Prado señalaría en 1864.

3. Es posible la presencia esporádica de sílex en la terraza baja del Manzanares desde las inmediaciones del puente de Praga. Este sílex procedería del nivel de arcillas marrones y verdosas ("gredas") miocenas -Unidad 3-, alcanzada en esta zona por el río, al llegar éste en su encajamiento a la cota de la terraza de $+8 \mathrm{~m}$ (Calvo Sorando et al. 1989: 14). Algunos nódulos y placas sin tallar de sílex vistos en El Sotillo (Pérez de Barradas y Wernert 1932: 33) pueden tener por tanto un origen natural. 
fundamentales alcanzadas para cada grupo tipológico, respetando los términos de la época, ya que son tanto la base de la interpretación de Obermaier y Wernert como de las propuestas posteriores de otros autores, que se apoyaron siempre en la publicación original de aquellos.

\section{Características de la industria de Las Delicias según Obermaier y Wernert}

- Hachas de mano de aspecto chelense, junto a otras mucho más perfectas, con una técnica de talla que relacionan con la de las puntas solutrenses (Ibid.p.33). Indican además que existen piezas que deben considerarse esbozos de estas hachas, abandonadas en el proceso de elaboración por sobrevenir alguna rotura accidental (Ibíd. p.22).

- Grandes raspadores y lascas con retoque lamelares que recuerdan núcleos del Paleolítico Superior, pero consideran que se trata de meros productos casuales, y no llegan a describir en detalle ninguno (Ibíd. p. 18)

- Utillaje variado sobre lasca de gran tamaño, alguna raedera gruesa, una lasca- raspador y un disco, así como lascas y láminas levallois.

- Entre los utensilios de menor tamaño mencionan una raedera doble, un raspador grueso y una punta amorfa, así como 4 láminas menores que las aludidas en el punto anterior.

Obermaier y Wernert no titubearon al afirmar que se trataba de una industria del Paleolítico Inferior. Descartaban el Superior, ya que en ese caso, decían, debería registrarse una proporción mayor de hojas. Los "tipos finos y delgados tallados por ambas caras" determinaban una definición como "achelense final clásico", pero no dejaban de recordar el ocasional aspecto solutrense de la talla: "Desde luego es notable que algunos de estos tipos finos recuerden por su perfección y talla cuidada las formas solutrenses". Tal posibilidad era inmediatamente descartada, recordando que en otras industrias achelenses superiores hay también materiales "pseudo-solutrenses". También consideraban la producción levallois impropia de un contexto del Paleolítico Superior (Ibíd.: 31-33).

El proceso responsable de la concentración de sílex reconocida, sería la actividad de talla (Ibíd::17-18 y 27). Los restos se habrían conservado en posición primaria o ligeramente removidos por los regueros formados por la lluvia, que es el origen que apuntaban para las arenas del nivel c. El reconocimiento de núcleos, productos de talla variados e incluso placas de sílex sin tallar les permitía fundamentar esta interpretación. Suponían también que en las cercanías existiría un campamento estable, dominando una llanura del Manzanares rica en caza (Ibíd.:18).

\section{3/ Pérez de Barradas y la investigación del Manzanares}

Las hipótesis que se emitieron posteriormente sobre Las Delicias están estrechamente ligadas al conjunto de trabajos desarrollados sobre el Cuaternario del Manzanares, sobre todo por Pérez de Barradas. En la trayectoria de este autor pueden separarse al menos dos etapas bien diferenciadas en las que se producirían sendas interpretaciones de Las Delicias. Esto implica que, para comprender la evolución de las ideas en la investigación del Manzanares, resulta fundamental tener presente el perfil biográfico de Pérez de Barradas, sus circunstancias laborales y las influencias que recibió en cada momento. Además, es necesario tener en cuenta que la brecha abierta por el abandono casi total del estudio del Paleolítico de la Meseta a lo largo de varias décadas, entre los años 40 y 70, determinó que toda la labor de aquellos años perdiera vigencia sin haber tenido continuidad. Contemplada cuatro décadas después, puede haber parecido inútil analizar como fueron evolucionando entonces conceptos e hipótesis, y percibirse una engañosa sensación de uniformidad. No fue así y merece la pena ponerlo de relieve. 
En 1917, siendo aún muy joven, José Pérez de Barradas (1897-1980) entró como becario en el Museo Nacional de Ciencias Naturales, y junto a Paul Wernert, ayudante de Obermaier desde los tiempos del I.P.H., formó desde el principio un equipo dedicado intensamente a la prospección de los yacimientos paleolíticos madrileños. El M.N.C.N. patrocinó las primeras actividades, hasta Julio de 1919, mientras que en los cinco años siguientes, hasta 1924, recibieron el respaldo económico de la Junta Superior de Excavaciones y Antigüedades. La formación de Pérez de Barradas al ingresar el Museo de Ciencias Naturales nos es desconocida, pero por sus primeros artículos, obras de juventud en definitiva, cabe deducir que no era aún muy especializada. Sabemos que más tarde, en 1923, se licenció en Ciencias Naturales y que en 1933 presentó una tesis doctoral de contenido etnológico -El color en el arte y en la vida de los pueblos-, disciplina a la que dedicó por completo su actividad profesional a partir de 1936, ocupando, además, una cátedra de Antropología en la Facultad de Medicina de la Universidad de Madrid después de 1939 (Priego 1982; de Carrera y Martín Flores 1997).

En su etapa inicial (1918-1924), los trabajos del dúo Wernert-Barradas están dominados por las ideas de Obermaier (1916, 1925), cuyos esquemas cronológicos y conceptuales, derivados del estudio glaciológico iniciado por Penck y de la escuela histórico-cultural centroeuropea (Pasamar y Peiró 1991), siguen al pie de la letra. Conviene tener presente la amplia formación de Obermaier, no sólo como prehistoriador-adquirida en Viena y París-, sino también como geólogo, ya que fue discípulo de Penck, con quien estudió el glaciarismo cuaternario. Obermaier ocupó en 1910 la cátedra de Geología del Cuaternario del Institut de Paléontologie Humaine (Moure 1996).

Wernert y Pérez de Barradas, como buenos discípulos del maestro, plantearon su actividad con la doble perspectiva paletnográfica y geológica que era de esperar. La primera consecuencia de ello fue que la lista de yacimientos prehistóricos en los $7 \mathrm{Km}$ del valle del Manzanares comprendidos entre San Isidro y Villaverde Bajo pronto fue ampliada sustancialmente ${ }^{4}$. Sin embargo, aunque en todo momento buscaron concretar la posición morfológica o la estratigrafía de las industrias, lo más significativo de su estrategia de investigación es que consideraban la tipología perfectamente válida para definir detallados períodos culturales (Chelense evolucionado, Musteriense inferior...), a los cuales se les asignaba sin margen de duda la cronología propuesta, con alcance general, por Obermaier. En definitiva, las características tipológicas de la industria lítica eran la clave que determinaba la cronología de los depósitos que la contenían. Este razonamiento llevó a considerar que todos los niveles de gravas del Manzanares -en los que identificaban industria Chelense- eran contemporáneos, proponiendo un proceso en el que alternaban vaciados y rellenos sucesivos para explicar la semejanza de las secuencias de niveles que reconocían a distintas alturas. De cada época, en la que se habrían depositado sedimentos de similar textura, se habrían conservado retazos adosados a los flancos del valle. A pesar de los trabajos de Hernández Pacheco sobre las terrazas de los principales ríos peninsulares (Hernández Pacheco 1928) o los de Royo en el mismo Manzanares (Royo et al.1929), Pérez de Barradas nunca llegó a modificar esta interpretación.

Por otra parte, es preciso reconocer que los escritos de Wernert y Pérez Barradas de estos años responden a planteamientos bastante elementales, puesto que prácticamente no iban más allá del registro de industrias y su asignación a un período cultural/cronológico. A veces se intentaban otro tipo de hipótesis, basadas en rudimentarias comparaciones de corte etnográfico y que sería interesante analizar en otra ocasión, pero esto era la excepción más que la norma. Sí queremos detenernos, sin embargo, en como el enfrentamiento fraguado en el seno de la C.I.P.P. entre investigadores nacionales -Cerralbo, Vega del Sella, Cabré y sobre todo, por la relevancia que tendrá en este tema, Hernández Pacheco- y extranjeros -Breuil y Obermaier fundamentalmente- trascendió a la actividad de los discípulos.

4. El balance de esta etapa de trabajos (Pérez de Barradas 1924) menciona 21 yacimientos estudiados en el término de Madrid y otros 13 en los municipios colindantes -Villaverde, Vallecas, Carabanchel Bajo y Pinto-. 
Desde la publicación de El Almendro (1919) Pérez de Barradas y Wernert aluden reiteradamente, en tono crítico, al desdén de los "geólogos" -se refieren habitualmente a E. Hernández Pacheco y a J. Royopor las industrias líticas, que les habría impedido reconocer la edad cuaternaria de parte del terreno que interpretaban como Terciario. Las diferencias de fondo entre ellos estaban en el crédito que concedían a la industria como fósil-guía para identificar períodos geológicos. Recordamos aquí estas polémicas, claramente inscritas en el terreno del choque surgido en el seno de la C.I.P.P., porque sirven de termómetro para conocer el alcance del enfrentamiento entre cuaternaristas y prehistoriadores, un conflicto que marcó derroteros separados para la actividad de unos y otros en los años anteriores a la Guerra Civil, e incluso se proyectó más allá de esas fechas.

Lo primero que determinó este trance fue la salida de Obermaier y Wernert, en 1919, de la Comisión de Investigaciones Paleontológicas y Prehistóricas y del Museo de Ciencias Naturales (Moure 1996). Sin embargo, gracias a sus importantes protectores -entre los que se contaba el Duque de Alba y la misma Casa Real-, Obermaier obtuvo en Julio de 1922, después de una intensa oposición de la Facultad de Ciencias y del mismo Hernández Pacheco, la primera cátedra de Prehistoria de la Universidad española, dotada en la Facultad de Letras de la Universidad Central de Madrid bajo el título de "Historia Primitiva del Hombre". En el mismo año fallecía el Marqués de Cerralbo y la C.I.P.P. entraba en franco declive, favoreciendo la posición preeminente del nuevo catedrático (Hernández Pacheco 1959: 719 ss.).

Desde la cátedra, en 1924 conseguiría Obermaier que el Ayuntamiento de Madrid aceptara cooperar en la organización del XIV Congreso Geológico Internacional. También logró que se nombrara a Pérez de Barradas delegado municipal en el evento. A partir de esta posición comenzó una fase de relativa independencia para el discípulo, afianzada a medida que el puesto en el Ayuntamiento se consolidó. En 1929 se creó el Servicio de Investigaciones Prehistóricas y el Museo de Prehistoria de Madrid, y Pérez de Barradas fue nombrado director (de Carrera y Martín Flores 1997).

Se inicia aquí una nueva etapa de trabajo, que va a caracterizarse por la mayor autonomía de Pérez de Barradas. Esta segunda y última fase concluye, como el mismo protagonista apunta (Pérez de Barradas 1936: 3), en 1931, y no en 1936 como se ha venido repitiendo hasta ahora de manera casi general. Tras la proclamación de la II República, los recursos económicos del Servicio municipal de Investigaciones Prehistóricas se redujeron drásticamente. La actividad de Pérez de Barradas acabó paralizada, al menos en lo que a trabajos de campo se refiere, reducida a la revisión de ciertas colecciones y otras actividades ocasionales cuyos resultados, en algún caso, se publicarían años más tarde (p. e. Pérez de Barradas 1941), produciendo una engañosa sensación de continuidad. En 1936, antes del pronunciamiento de Franco, Pérez de Barradas había cambiado definitivamente su actividad investigadora de la Prehistoria a la Etnología. En mayo de ese año aceptó un contrato del Ministerio de Educación de Colombia (Carrera y Martín Flores 1997). Al volver, finalizada la Guerra, sería repuesto en el Museo y el Servicio municipal de Arqueología, pero la falta de medios y sus inmediatos nombramientos como director del Museo Nacional de Etnología y del Museo del Pueblo Español, le alejaron definitivamente de las actividades arqueológicas (Quero 1996).

Después de 1940 la investigación en el Manzanares tardó algún tiempo en reactivarse. El Servicio Municipal permaneció inactivo desde el abandono de Pérez de Barradas hasta 1953, fecha en la que se crea el Instituto Arqueológico Municipal (Parque de la Fuente del Berro), del que se nombra a J. Martínez Santa Olalla director vitalicio (Quero 1996). A partir de ese momento hubo un cierto repunte de las prospecciones en el Manzanares e incluso alguna excavación, como la de un cráneo de elefante en Orcasitas en 1959 (Quero 1994). También puede recordarse la intervención de este Instituto en algunos congresos internacionales, en especial en el de Ciencias Prehistóricas celebrado en España en 1954, y en el V y VI Congresos de la INQUA (Madrid 1957 y Varsovia 1961). Pero fueron trabajos sin demasiada proyección, ya que no dieron lugar a publicaciones científicas, ni se plasmaron en verdaderos proyectos de investigación, puesto que no llegaron a formarse equipos capaces de acometerlos. 


\section{4/ Sucesivas hipótesis sobre el yacimiento de Las Delicias}

El marco historiográfico descrito en el apartado anterior servirá para contextualizar y comprender mejor las hipótesis formuladas sobre el yacimiento de Las Delicias.

La primera revisión de la interpretación inicial corresponde al momento en que Pérez de Barradas está ya asentado en el Servicio Municipal de Prehistoria. Desde la excavación de 1918, la lista de yacimientos paleolíticos en el Manzanares había crecido considerablemente y parecía llegado el momento oportuno para una nueva síntesis, ya que Obermaier y Pérez de Barradas (1924) manejaban nuevas ideas basándose en un conjunto de 34 yacimientos considerados musterienses. Sus puntos de vista se iban a apoyar también en las últimas sistematizaciones de las épocas prehistóricas que Breuil, y también Peyrony, estaban planteando, basados en esquemas historicistas más complejos que el evolucionismo unilineal propuesto en la segunda mitad del siglo anterior por Mortillet y que todavía impregnaba las construcciones de Obermaier en $E l$ Hombre Fósil. Pero la "cronología tipológica" de Mortillet aun se proyectaba, aunque aceptando ahora que los conjuntos industriales correspondían a etnias diferentes. Las industrias de tipo musteriense, por ejemplo, se suponían propias de pueblos que se estaban desplazando desde el centro de Europa hacia el Sur y el Oeste, en pugna con los aborígenes "achelenses". En la Península estas tensiones entre dos tradiciones culturales (etnias) diferentes, se verían complicadas por la presencia de grupos de procedencia norte-africana.

En el Manzanares se reconocía una abigarrada secuencia Musteriense, apoyada en la tipología de la industria y en la interpretación climática y cronológica de cada uno de los depósitos distinguidos en los areneros, siempre conforme al modelo de construcción del valle propuesto por Pérez de Barradas (1923) y asumido por Obermaier (1925: 162). Esto dio lugar (Obermaier y Pérez de Barradas 1924) a la siguiente sucesión de niveles-culturas musterienses:

- 1/ Tránsito Achelense-Musteriense

- 2/ Musteriense Inferior de tradición achelense con las primeras influencias africanas

- 3/ Musteriense Inferior

— 4/ Musteriense de tradición achelense e influencia Esbaikiense

- 5/ Musteriense Medio

- 6/ Musteriense Medio de tipos pequeños

- 7/ Musteriense Medio de tradición achelense

- 8/ Musteriense Superior de tipos pequeños

- 9/ Musteriense ibero-mauritano

- 10/ Musteriense Final

Las Delicias se situaba en el cuarto de estos episodios. Mientras que algunas "hachas sobre lasca" -un típico hendedor, como más adelante veremos-permitían hacer comparaciones con el Musteriense de Tradición Achelense de la región cantábrica, los bifaces planos de contorno foliáceo se consideraban semejantes a los señalados en el Esbaikiense norteafricano ${ }^{5}$, una cultura que se creía paralela al Achelense Superior europeo.

En los años inmediatamente siguientes Pérez de Barradas continuó manteniendo el mismo esquema para el Musteriense, tal y como se percibe en la notable síntesis de 1926 sobre el Cuaternario de Madrid, en la que aún es patente la huella de Casiano de Prado (Pérez de Barradas 1926).

Las primeras reservas que recibió tan complejo mosaico de industrias partieron de los geólogos (Royo et al. 1929) del Museo de Ciencias Naturales -formados junto a Hernández Pacheco y herederos del espíritu interdisciplinar de la C.I.P.P.-. Para ellos la tipología no podía justificar diferencias tan sutiles de industrias, toda vez que las contaminaciones de piezas procedentes de niveles más altos suponían un factor que no

5. Una discusión sobre este asunto, desde una perspectiva actual en Enamorado 1984. 
se había tenido en cuenta. Por otro lado abogaban por una secuencia de niveles sucesivos de terrazas, que poco tenía que ver con las ideas de excavación y relleno total del valle mantenidas por Pérez de Barradas y Obermaier. Desde estas posiciones era obvio rechazar la multiplicidad de periodos propuestos por estos autores y seguir considerando Achelense superior el conjunto de Las Delicias.

Los planteamientos principales de Royo no fueron asimilados por Pérez de Barradas, que, sin embargo, comenzaría a aproximarse progresivamente a las tesis polifiléticas de Breuil. Esta opción le llevaría también a centrarse en la tipología y el estado de conservación de la industria -pátinas y rodamiento-y desentenderse un tanto de los aspectos geológicos, más atendidos en la etapa precedente, en la que la influencia de Obermaier resultaba exclusiva.

Aún así las interpretaciones africanistas aplicadas al Paleolítico inferior y medio eran patentes todavía en 1929, cuando Pérez de Barradas distinguía un horizonte Pre-Capsiense, anterior al Achelense Superior, provocado por la llegada de gentes norteafricanas y caracterizado por una mezcla de caracteres propios del capsio-auriñaciense con elementos precursores del Musteriense y reminiscencias "chelleo-acheulenses" (Pérez de Barradas 1929: 269-272). A partir de 1932 la influencia de Breuil llevará a Pérez de Barradas a olvidar poco a poco el papel de las influencias africanas en el Paleolítico antiguo del Manzanares. El primer atisbo de este cambio de actitud creemos apreciarlo en la recensión de "Le Clactonien..." (Pérez de Barradas 1932), donde acepta ya la existencia de un Clactoniense-cultura, aunque hasta el Manzanares llegara fundamentalmente como una influencia en las técnicas de talla "chelleo-acheulenses".

En 1934 aparece un artículo en el que aún acepta las influencias africanas (1934: 4-5), pero también otro (Pérez de Barradas 1934a) en el que manifiesta cambios sustanciales que inciden de manera directa sobre Las Delicias. Este yacimiento vuelve a ser valorado de manera parecida a como lo había sido inicialmente, Achelense Final o Achelense VIII de Breuil, renunciando de forma explícita Pérez de Barradas a la anterior filiación Mustero-Esbaikiense. Las influencias del Sur se ven sustituidas por las del Norte, dentro del cambio general de escenarios, que no de perspectivas, postulado por Breuil.

Es interesante constatar, en cualquier caso, como en esta última fase Pérez de Barradas se alejó de las posiciones nacidas del magisterio de Obermaier y modificó sustancialmente la interpretación del Paleolítico Inferior del Manzanares. Desaparecen de su esquema las industrias chelenses, que sólo menciona, junto a Clactoniense I, rodadas y patinadas -procedentes de una terraza superior- en las gravas de San Isidro. Paralelamente cobra protagonismo el Achelense, un período subvalorado en la crono-secuencia de Obermaier.

En el nuevo sistema la industria de las gravas inferiores de San Isidro correspondería al Achelense inferior y al Clactoniense II, y dataría, aplicando los postulados de Breuil al pie de la letra, del segundo período interglacial (Mindel-Riss). Las influencias africanas se relegan ahora a las etapas finales del Paleolítico, para las que se acuña el concepto de "Matritense". Esta fase local del Paleolítico Superior, en la que Pérez de Barradas diferenciaba tres estadios, englobaba fundamentalmente las series antes denominadas "Musteriense ibero-mauritano". En ella reconocía un fuerte núcleo de tradiciones antiguas, levalloisienses y musterienses, junto a influencias aterienses y esbaikienses, modificadas por elementos auriñacienses y solutrenses. Finalmente las industrias magdalenienses cerraban el ciclo paleolítico del Manzanares (Pérez de Barradas 1934b).

En el estudio de la colección Bento (Pérez de Barradas 1936) se desarrolla algo el esquema anterior, siempre defendiendo un mecanismo de fases sucesivas de incisión y relleno total del valle, de manera que los niveles de gravas a muro de San Isidro y de las terrazas de menor cota-las superiores a San Isidro se llevan al Plioceno- corresponderían todos al segundo interglacial y contendrían industrias achelenses coetáneas.

En este punto quedó el estudio del Manzanares tras un par de décadas de intenso trabajo de campo. Posiblemente faltó tiempo para alcanzar interpretaciones más maduras. La opinión de los investigadores que se ocuparon del Paleolítico de la Península ibérica a partir de 1940 parece incidir en el carácter provisional de las últimas síntesis precedentes, marcadas por su carácter apriorístico derivado de la aplicación casi mecánica de los esquemas breuilianos (Santa Olalla 1941, citando la opinión del Conde de la Vega del Sella). 
Los manuales y obras de síntesis sobre el Paleolítico español hasta la década de los sesenta se limitan a resumir y barajar los datos e hipótesis adquiridos en 1918-1934, o reutilizan dicho material a partir de lecturas incompletas y mezclando ideas de momentos diferentes, hasta el punto de hacer ininteligible el discurso. Merece la pena en todo caso recordar que algunas opiniones sobre Las Delicias aproximan de nuevo al Musteriense su industria. En primer lugar hay citar a G. Freund, cuya investigación se centró en las estaciones Presolutrenses de Europa Central con puntas foliáceas, bifaces, raederas y puntas musterienses, y que señaló el conjunto de Las Delicias como un notorio paralelo de ese mundo (Freund 1952). Para F. Jordá la industria de este yacimiento correspondería a un Musteriense con "puntas bifaciales tenuifoliadas" paralelo al Szeletiense, aunque sin relación alguna de filiación (Jordá 1955)

La falta de hipótesis novedosas se relaciona sin duda con la inexistencia de nuevos trabajos de campo. Cuando Freeman, en 1975, analiza las investigaciones de 1914-1934 en el Manzanares, por primera vez desde una perspectiva metodológica moderna, tiene que basarse en datos antiguos e intentar contrastar observaciones ampliamente superadas en el marco de la teoría general, pero que, al fin y al cabo, seguían siendo las últimas realizadas en el contexto del río madrileño. Lamentablemente carecía de nuevas excavaciones que aportaran una base adecuada para reinterpretar la información conocida ${ }^{6}$.

La visión que ofrece de Las Delicias (Freeman 1975: 683 ss.) se basa en la publicación de Obermaier y Wernert, en la evaluación de la industria conservada en el Museo Nacional de Ciencias Naturales y en la posición morfoestratigráfica que supone para el yacimiento. En cuanto al segundo de estos aspectos, considera que se trata de una industria homogénea, asignable al Achelense Superior, aunque también valora ciertos paralelismos con el Musteriense de Tradición Achelense cantábrico, como en 1918 habían observado Obermaier y Wernert. Coincide también con estos autores en reconocer un área de talla, apreciando la existencia de bifaces muy planos fracturados posiblemente por accidentes de talla y otros abandonados en el curso de su elaboración, quizás por problemas de la materia prima. No comenta Freeman, sin embargo, la posibilidad de que el sílex haya sido introducido por los humanos en el yacimiento ${ }^{7}$, como apuntaban ya en 1918 Obermaier y Wernert y recogerían posteriormente, entre otros, Royo y Pérez de Barradas.

En cuanto a la posición morfoestratigráfica, para Freeman (1975: 693-694) Las Delicias se encontraría en la terraza de $+15 / 25 \mathrm{~m}$ del Manzanares, lo cual, como veremos, es erróneo, pues este yacimiento queda fuera del sistema de terrazas del río madrileño. Al considerar que la industria debía datarse en la última glaciación, Freeman se veía obligado a aceptar esa edad para el resto de los yacimientos localizados en dicha terraza, varios de ellos claramente achelenses como Parador del Sol ${ }^{8}$.

Más recientemente se ha valorado Las Delicias como sitio de talla Achelense Superior o Musteriense bien conservado (Santonja y Querol 1980; Rus 1987: 28), apuntando hacia el interés del yacimiento en relación con el modelo de aprovisionamiento de materias primas en el Manzanares (Baena, 2000: 92-93). Es interesante, para completar la visión histórica de Las Delicias, mencionar que en estos últimos años se ha vuelto a sugerir la posibilidad de que se trate de una industria Solutrense (Baena et al. 2000: 90).

6. Por otra parte hay que señalar que Freeman maneja de forma incompleta la bibliografía. Con excepción de la publicación de El Sotillo, no tiene en cuenta las aportaciones de Pérez de Barradas posteriores a 1926, y tampoco publicaciones fundamentales de principios de los años 70 que comenzaban a establecer nuevas bases para el estudio de las terrazas de la región de Madrid.

7. En otras publicaciones posteriores, alguna específicamente dedicada a la problemática de las materias primas en el paleolítico de la Península Ibérica, tampoco se ocupa de la interesante cuestión de la utilización del sílex en los yacimientos paleolíticos del valle del Manzanares (Freeman 1991; González Echegaray y Freeman 1998).

8. Esta misma interpretación se ha mantenida posteriormente (González Echegaray y Freeman 1998: 54-55). 


\section{II- EL CONTEXTO GENERAL DEL MANZANARES Y LA ESTRATIGRAFÍA DE LAS DELICIAS}

\section{1/ Las formaciones del Manzanares y los restos arqueológicos. Aspectos generales}

El área excavada por Obermaier y Wernert se sitúa en la orilla izquierda del Manzanares, a una altitud absoluta de $590 \mathrm{~m}$ y unos $20 \mathrm{~m}$ sobre el cauce actual del río.

El Manzanares desarrolló un importante sistema de terrazas, que subsiste casi exclusivamente en la margen derecha. En la parte Norte de Madrid se conservan las secuencias más completas en La Zarzuela y la Casa de Campo. Se han identificado en este sector trece niveles escalonados a alturas relativas de $+3 / 5 \mathrm{~m}$ (llanura aluvial), $+8 \mathrm{~m},+10 \mathrm{~m},+12 / 15 \mathrm{~m},+18 / 20 \mathrm{~m},+25 / 30 \mathrm{~m},+35 / 40 \mathrm{~m},+44 / 46 \mathrm{~m},+52 / 54 \mathrm{~m},+60 \mathrm{~m}$, $+68 / 72 \mathrm{~m},+80 / 85 \mathrm{~m}$ y +90/94 m Aguas abajo, ya en pleno Madrid, entre el arroyo de Los Meaques y la depuradora de Butarque, se conservan sólo niveles medios y bajos, escalonados a cotas de $+8 \mathrm{~m},+12 / 15 \mathrm{~m}$, $+18 / 20 \mathrm{~m}$ y $+25 / 30 \mathrm{~m}$ (Goy et al. 1989)

En la terraza de $+25 / 30$ m se encuentran situados yacimientos achelenses como San Isidro, Transfesa y Orcasitas, con faunas caracterizadas por Elephas (Palaeoloxodon) antiquus platyrinchus y Praedama sp. Éste último megacerino, solamente señalado en Transfesa, presenta cierto carácter arcaico dentro del Pleistoceno Medio, y llevaría la cronología de la terraza hacia el límite Bihariense-Toringiense (Sesé y Soto 2000), en torno a los estadios isotópicos 11-13 (Santonja et al 2001). Por las terrazas siguientes se reparten la gran mayoría de los yacimientos clásicos, dados a conocer por Pérez de Barradas y Wernert. En la terraza de $+18 / 20$ m parecen existir industrias achelenses y fauna (Elephas antiquus en Parador del Sol, $c f$. Royo et al. 1929) con cronologías del final del Pleistoceno Medio, mientras que los dos niveles siguientes, $a+12 / 15 y+8 m$, corresponderían al Pleistoceno Superior. A techo de la terraza inferior, $+8 \mathrm{~m}$, se sitúan yacimientos del Paleolítico Superior, caso de El Sotillo, por lo que al menos este tramo estratigráfico puede fecharse en el estadio isotópico 2, aunque la terraza en sí se construyera en un momento anterior.

Más adelante, desde el arroyo de Butarque, los niveles reconocidos en el tramo anterior aparecen sobreimpuestos, encajados unos en otros, dando lugar a la terraza compleja de Butarque (Goy et al. 1989), cuya base está por debajo de la llanura aluvial actual. En este tramo (Rus 1987), continúan apareciendo yacimientos de cronologías comprendidas en todo el margen temporal indicado, aunque en este caso las cotas en que se sitúan no permitan establecer relaciones directas con las terrazas del tramo anterior.

No es adecuado interpretar el alto número de "yacimientos" paleolíticos del área de Madrid como indicio de una concentración de población en el Pleistoceno Medio y Superior, motivada por condiciones medioambientales favorables, como se repite con frecuencia. La abundancia de restos -y sería conveniente reservar el término yacimiento para concentraciones bien delimitadas de restos claramente vinculadas con actividades o procesos antrópicos-está relacionada con los fenómenos de subsidencia sinsedimentaria que han afectado al tramo final del valle del Manzanares desde el Pleistoceno Medio (Pérez-González 1971 y 1980), los cuales han determinando mayores acumulaciones de sedimentos arenosos y de fangos de llanura de inundación. En estos depósitos, que poseen espesores superiores a $10 \mathrm{~m}$ a partir de San Isidro, los restos de fauna y la industria lítica se han conservado mejor que en las terrazas de gravas típicas de otros cursos fluviales de la Meseta o del mismo Manzanares aguas arriba, en los perfiles de la Casa de Campo o La Zarzuela.

\section{2/ Geología de Las Delicias}

El yacimiento de Las Delicias se encuentra situado sobre depósitos terciarios de arcillas verdes y rosadas, arenas, margas y niveles de carbonatos y sílex (Calvo Sorando et al. 1989). Los datos estratigráficos aportados por Obermaier y Wernert (1918), junto con el reconocimiento que hemos realizado del entorno del yacimiento, permiten efectuar algunas consideraciones preliminares sobre la génesis de los depósitos que lo conforman. 
Desde un punto de vista geomorfológico, el yacimiento se encuentra en un área de interfluvio entre el río Manzanares, al Sur, y el arroyo del Hospital, al Norte. Esta zona se estructura en una plataforma a unos + 35/40 m sobre el río Manzanares y una vertiente con suave caída hacia mediodía, que es donde se ubica el yacimiento y la estación de Las Delicias, a +20/25 m sobre el Manzanares. En este sector no se reconocen depósitos fluviales pertenecientes a terrazas de este río.

La estratigrafía publicada (Obermaier y Wernert 1918) y la geometría y contactos entre las distintas capas diferenciadas (fig. 3) sugieren depósitos de origen local, en un medio tractivo de baja energía, pero capaz de incorporar clastos arcillosos (mud-balls) arrancados del sustrato (capa c, fig. 3), asociado a sedimentos finos con componente principal de acreción vertical (capa b, fig. 3) donde, sin embargo, se localizan gravas dispersas que indican remociones y aportes laterales o de aguas arriba.

Los estratos $\mathbf{c}$ y b tienden a acuñarse hacia el NNW (figs. 2 y 3), lo que junto con la cicatriz erosiva observable sobre el Terciario en el corte estratigráfico CD (fig. 3), parece confirmar que esta morfología y los depósitos descritos corresponden a una pequeña vaguada de drenaje deficiente que fluiría hacia el río Manzanares. También es posible que ese flujo o flujos alimentaran a una reducida zona de características endorreicas situada en lo que hoy es el Museo del Ferrocarril.

A partir de las descripciones estratigráficas y texturales ofrecidas por Obermaier y Wernert (1918), se ha podido identificar la capa $\mathbf{b}$ en un pequeño talud artificial, inmediatamente al norte del yacimiento, a la salida hacia el sur de la estación de Cercanías de Delicias, y en solares próximos de la calle Ramírez de Prado en obras. Se trata de una marga arcillosa detrítica que rompe en agregados pseudo-prismáticos, de color oliva (5Y 5/2), y contiene abundantes nodulizaciones y concreciones de carbonato cálcico edáfico. Este carbonato recubre de una manera discontinua y delgada los clastos y los sílex tallados presentes. Se trata de una acción edafogenética que por su intensidad puede derivar de la evolución de un horizonte $\mathrm{C}_{\mathrm{k}}$, del perfil de un suelo con una cronología antigua, del Pleistoceno Superior posiblemente, sin que por el momento sea posible una precisión mayor.

\section{III- LA INDUSTRIA LÍTICA DE LAS DELICIAS}

\section{1/ Características de la serie conservada}

En el Museo Nacional de Ciencias Naturales de Madrid se conservan algunos materiales procedentes de la excavación de Las Delicias. Este conjunto corresponde casi exactamente con la colección publicada por Obermaier y Wernert. Faltan tres piezas, dos bifaces (Obermaier y Wernert 1918: figs. 10 y 11) y lo que parece el extremo de otro (o.c. fig. 27) y hay algunas otras, lascas no retocadas y núcleos, no ilustradas en la publicación, pero cuya procedencia del yacimiento no ofrece dudas, ya que las siglas que conservan son semejantes a las del resto.

En total hemos revisado 37 piezas, entre las que hay dos fragmentos de sílex que parecen desprendimientos térmicos, y podemos evaluar con ciertas garantías las tres piezas en paradero desconocido a partir de sus detallados dibujos. Tenemos, por tanto, información de 38 piezas talladas, una cifra ciertamente reducida y que corresponde, además, a una selección drástica. Por esta razón nos limitaremos a realizar un estudio de las características de los grupos morfo-técnicos que pueden diferenciarse, sin intentar un análisis más detallado de la serie ante lo incierto de las conclusiones que pudieran obtenerse. Creemos en todo caso que esta evaluación puede ayudar a comprender mejor el yacimiento y, sobre todo, a plantear algunas cuestiones que pudieran ser objeto de futuras investigaciones. Debe tenerse también en cuenta que parte de estas piezas procedían de la superficie, de acuerdo con las inscripciones que presentan, pero dado su escaso número las analizaremos junto a las demás, aunque no olvidamos que Obermaier y Wernert apuntaran la existencia de cierta dispersión estratigráfica. Dejaremos constancia de cuales son. 
Con excepción de una lasca sin retocar y un cuchillo de dorso natural, de cuarcita, en el resto de la serie la materia prima empleada son distintas variedades de sílex y chert. El estado de la superficie de las piezas es bastante similar en cuanto al desgaste; aristas y filos aparecen en general ligeramente redondeados y apenas hay alguno absolutamente fresco, aunque tampoco se aprecian ejemplares con rodamiento marcado. Da la impresión de tratarse de materiales no sometidos a acción hídrica continuada, aunque ocasionalmente puedan haber sido afectados por algún tipo de desgaste fluvial. Un porcentaje significativo presenta pátinas blancuzcas o costras calcáreas ligeras. También se observan con frecuencia lustres que parecen de probable origen térmico, asociados a veces con grietas (cuarteado), e incluso algún desprendimiento aparentemente de este origen - p. e. en un núcleo levallois, fig. 5, n 3-, o dos fragmentos, quizás recogidos como lascas, ambos procedentes de la superficie, que parecen tener este origen y no hemos tenido en cuenta en nuestro estudio.

Consideraremos las características de los productos de talla (lascas y láminas no levallois, lascas levallois), núcleos y utensilios, desglosando los que se distinguen por presentar filo natural, las lascas retocadas y el utillaje bifacial.

- Productos de talla no levallois: se reconocen lascas y láminas levallois y no levallois. A pesar de tratarse de un conjunto seleccionado, hay ocho lascas no levallois sin retocar. Todas son no corticales y sólo una presenta talón facetado, aunque hay otras dos con talones lisos reducidos. Su tamaño medio es de 44 x $31 \mathrm{~mm}$, sensiblemente menor al de las lascas retocadas. La mayoría-cinco-consta que se recogieron en superficie, y otra procedería de la “capa superior”. Quizás esta sea la razón de haber conservado lascas ordinarias, al faltar productos más elaborados con estas procedencias.

- Productos de talla levallois: hay una notable presencia levallois en la colección, cinco lascas y una lámina no retocadas, además de una punta de primer orden-algo desviada (retocada), y un hendedor sobre una gran lasca levallois. Tres -cuatro, si incluimos el soporte del hendedor-de las lascas (fig. 4, $\mathrm{n}^{\text {os }} 1,3,4$ y 7) proceden de núcleos cuya superficie principal se gestionó de forma centrípeta, mientras que las otras dos lascas, y también la punta (fig. $4, \mathrm{n}^{\text {os }} 5$ y 6 ; fig. $6, \mathrm{n}^{\circ} 1$ ), se extrajeron en superficies levallois con gestión unipolar. Una lámina al menos (fig. $5, \mathrm{n}^{\circ} 5$ ), veremos que hay otras, puede proceder de un núcleo levallois de láminas más o menos clásico. Sin incluir el hendedor (141 x $105 \mathrm{~mm}$ ), la dimensión media de estos productos es de $85 \times 50 \mathrm{~mm}$, netamente superior al de las lascas no levallois. Todas estas piezas aparecen dibujadas en la publicación de los excavadores, por lo que no hay ninguna duda acerca de su procedencia del nivel basal.

- Otras láminas: hay otras tres láminas que no es posible establecer si proceden de núcleos levallois o de verdaderos núcleos prismáticos de tipo Paleolítico Superior (cf. Révillion 1994: 289). Una de ellas está completa, es de gran tamaño $(121$ x 59 × $16 \mathrm{~mm})$ y presenta negativos bipolares en la cara superior (Obermaier y Wernert 1918: fig. 17). Las otras, una completa $(58 \times 26 \times 10 \mathrm{~mm})$ y otra un fragmento mesial (o. c., fig. 23), presentan negativos unipolares y paralelos en el anverso. Su procedencia del nivel basal también es segura.

— Núcleos: hemos identificado dos, uno de ellos levallois (fig. 5: 3), de modalidad recurrente, gestión centrípeta y ultra-explotado (lateral izquierdo). El segundo es un núcleo discoide no levallois (fig. 5: 1), con extracciones centrípetas en ambas caras, en el que posiblemente se empleó como soporte una gruesa lasca. El núcleo levallois procede de la superficie.

- Percutor: se conserva en la serie un nódulo subesférico de sílex que pudiera haber servido como percutor $(60 \times 58 \times 57 \mathrm{~mm} ; 200 \mathrm{~g})$. Presenta múltiples fisuras y lustre de origen térmico, pero no se han observado las huellas de impactos típicas de un uso como percutor. Recordemos en todo caso que el sílex debió ser introducido en el yacimiento.

- Utensilios retocados: además de la punta levallois, ya mencionada, con retoque denticulado en un lateral (fig. 6: 1), hay cuatro raederas, una escotadura retocada y un raspador. Entre las raederas 
sobresale una desviada de gran tamaño (128 x 90 x 35 mm, fig. 6: 5), con retoque profundo directo. Hay otra raedera algo denticulada desviada, también con retoque directo, más pequeña ( $45 \mathrm{~mm}$ de longitud), y dos convexas, una de ellas adelgazada (fig. 6:3) y la otra transversal (fig. 6: 2). Finalmente una escotadura doble retocada y un raspador espeso y con el frente algo denticulado, más bien atípico (fig. 6: 4). Todas estas piezas proceden con seguridad del nivel basal de Las Delicias.

- Utensilios con filo natural: tres piezas, un hendedor y dos cuchillos de dorso. El hendedor es de tipo III (Tixier 1956)-sobre lasca levallois-, perfectamente equilibrado, con percusión Sur y retoque en ambos lados y en la base (fig. 4: 1). Uno de los cuchillos de dorso es de gran tamaño (145 x $102 \mathrm{~mm}$; fig. 4: 2), el dorso está formado por el talón de la lasca, que incluye una amplia superficie del plano de percusión del núcleo -que en esta zona se explotó de forma unipolar, con extracciones más o menos paralelas a partir de una plataforma de percusión lisa no cortical-. El segundo cuchillo de dorso (fig. 6: 6) es una lasca de cuarcita con dorso cortical, de "gajo de naranja", un producto habitual de la talla de cantos rodados de sección oval. Proceden con seguridad del nivel basal.

- Bifaces: hay cinco bifaces en la colección del M.N.C.N. y otros tres más descritos en la publicación de Obermaier y Wernert, no conservados, pero que también tendremos en cuenta. Todos proceden del nivel basal. El único que se conserva completo es un bifaz amigdaloide ${ }^{9}$ con base espesa, tallado mediante percutor duro exclusivamente, sobre una lasca o un fragmento tabular de sílex (fig. 7:2). Los restantes no están completos, ya que presentan fracturas, fenómeno en el que más adelante nos detendremos, que interesan distintas porciones de su superficie. Otra característica común a este grupo es que en todos ellos se observan, aunque con diferente intensidad, extracciones efectuadas mediante un percutor orgánico o de piedra muy poco pesado. De los tres no conservados, uno, con $59 \mathrm{~mm}$ de longitud, corresponde al extremo distal y el soporte podría ser una lasca (Obermaier y Wernert 1918: fig. 27). Los otros dos, más completos, son bifaces lanceolados, uno quizás cordiforme alargado (fig. 5: 2 y 4). Al más completo de la serie del M.N.C.N. le falta tan sólo una pequeña porción basal (fig. 8: 2); se talló a partir de una lasca kombewa y presenta contorno ovalar, bastante plano (m/e =3,86). Otro (fig. 7: 1) corresponde aproximadamente a las dos terceras partes de la pieza original, un bifaz subcordiforme o subtriangular $(\mathrm{m} / \mathrm{e}=2,4)$. Hay un fragmento basal o apical de una pieza en proceso de elaboración (o. c. fig. 12) y la parte distal de un gran bifaz cordiforme o lanceolado ( $\mathrm{L}>112 \mathrm{~mm})$, muy plano $(\mathrm{m} / \mathrm{e}>3,65)$, con talla uniforme de percutor elástico y fractura doble basal (fig. 8: 1).

\section{2/ Consideraciones preliminares sobre la industria lítica}

El número reducido de piezas y, sobre todo, el carácter selectivo de la muestra estudiada confiere sin lugar a dudas un carácter provisional a las hipótesis que vamos a plantear, limitándonos en cualquier caso a considerar los aspectos globales y cualitativos observados que consideramos más significativos.

La inexistencia de subproductos de talla -fragmentos amorfos, debris, chunks ...- no debe extrañar en una muestra que tiene un marcado carácter selectivo. En principio cabe suponer que este tipo de materiales debería ser muy abundante y su falta confirma la profunda selección efectuada. Incluso pueden echarse de menos más percutores y otros bloques de materia prima simplemente probados, que también tenían que ser frecuentes si en efecto se trataba de un taller. Tampoco es posible conceder crédito absoluto a la débil presencia de cuarcita -roca en cualquier caso también ajena al medio geológico-, aunque la inexistencia de productos acabados en esta roca significa sin duda que se utilizó en menor medida que el sílex.

9. En la clasificación de los bifaces seguimos el método Bordes (Bordes 1961). 
De los productos levallois observados, tanto de su morfología como del tamaño, se podría deducir el dominio de este método de talla, aunque la tremenda selección efectuada imponga alguna cautela. Comprobamos la existencia al menos de superficies levallois recurrentes, explotadas según una secuencia centrípeta, y también superficies con extracciones unipolares. Tal vez podrían haber existido también núcleos de puntas y de láminas, aunque debe tenerse en cuenta que algunas de éstas pudieron extraerse también en núcleos de tipo Paleolítico Superior, con secuencias de extracciones subparalelas guiadas desde el principio por las nervaduras de los primeros negativos, idénticas en cualquier caso a las que es posible obtener una vez avanzada la explotación en superficies preparadas mediante la variante uni o bipolar del método levallois.

La presencia de núcleos si, insistimos, estamos ante un taller, debería ser más elevada que lo acusado en la muestra estudiada. Cabría pensar que los núcleos levallois o discoidales bien conformados no eran frecuentes, predominando soportes menos característicos como parece desprenderse de algún pasaje de la publicación original ("núcleos por lo ordinario toscos y pesados", o.c. p. 18). En varios utensilios (p. e. figs. 4: 2 y 7:2) se acusa la presencia de restos de superficies muy planas que indican el empleo de sílex tabular, y de hecho Obermaier y Wernert mencionan la existencia de placas de sílex con costra adherida (1918: 17). Quizá existiera en Las Delicias cierta profusión de núcleos con una configuración sólo esbozada -con un aspecto que no favorecería su selección si se efectuó con criterios formales -, en los que se pudiera haber desarrollado una gestión unipolar de las superficies a partir de planos de percusión lisos. Alguna observación en la publicación original - presencia de "lascas con retoques lamelares que recuerdan núcleos del Paleolítico Superior", que no se recogieron (Obermaier y Wernert 1918: 18)- quizás se refiera a este tipo de soportes.

El utillaje sobre lasca es escaso, pero su aspecto corresponde perfectamente a un conjunto del Paleolítico Medio. La configuración de las raederas y el estilo del retoque que presentan no son propias del Paleolítico Superior. El único raspador, sobre una gruesa lasca y algo denticulado, encaja en aquel contexto. Las "piezas foliáceas" creemos que pueden considerarse en todos los casos bifaces. Los más acabados de estos (figs. 5: 2 y 4; 7: 1; 8:1 y 2) sugieren desde luego una atribución al Achelense Superior o al Musteriense, permitiendo descartar, casi con seguridad, industrias anteriores.

En definitiva no nos parece probable que pueda corresponder al Paleolítico Superior este conjunto $(c f$. Baena et al. 2000: 90), a pesar del estilo del retoque mediante percutor blando de varios ejemplares, aspecto ya discutido y rechazado por Obermaier y Wernert. Interpretar como puntas solutrenses en proceso de fabricación algunas de las piezas bifaciales no parece tampoco convincente. La mayor de ellas (fig. 8: 1), perfectamente simétrica, hay que considerarla prácticamente acabada en el fragmento conservado, y posee unas dimensiones que no justifican una clasificación como punta, al menos en el sentido clásico del término (Brezillon 1977: 292 ss.).

Tampoco el lustre de posible origen térmico en una lasca ordinaria, en el posible percutor, la raedera transversal, el núcleo levallois (con un estallamiento térmico además), una de las lascas levallois, un fragmento mesial de lámina y en los bifaces (salvo en el amigdaloide espeso), puede ser un argumento de peso a favor de una cronología avanzada de esta industria. Podría pensarse que nos encontramos ante un tratamiento térmico relacionado con el empleo de percutor blando en el retoque, pero vemos que hay piezas en las que esta relación carece de sentido (especialmente en el percutor y el núcleo). Nos inclinamos a pensar que se trata de calentamientos con otro origen, sin que sea descartable una causa natural o en todo caso involuntaria.

Precisamente la profusión de utensilios fracturados aporta el argumento de más peso - una vez visto el escaso número de lascas y núcleos presentes-para considerar que Las Delicias era un taller. Prácticamente la totalidad de los bifaces y los útiles sobre lasca de mayor tamaño presentan una o más fracturas. Prescindiendo de algunas lascas y utensilios menores, las hay en el hendedor (fig. 4: 1), en la raedera transversal y en la raedera desviada (fig. 6: 2 y 3), así como en todos los bifaces, incluidos los tres no conservados en el M.N.C.N. (figs. 5: 2 y 4; 7: 1; 8: 1 y 2), excepto uno, precisamente el único tallado exclusivamente 
con percutor duro (fig. 7: 2). Se trata en casi todos los casos de fracturas limpias, planas, perfectamente ortogonales al plano principal de la pieza y en las que no se reconocen puntos de impacto u otros caracteres que permitan identificar que causa pueda haberlas originado. Sólo en el bifaz subcordiforme o subtriangular se observa un contrabulbo en el centro de la fractura (fig. 7: 1; lám. II: 3) que puede sugerir un gesto intencionado para producir una base espesa. Algo similar, pero menos claro, pudiera deducirse de las ligeras pestañas que presentan en el borde superior las fracturas del bifaz lanceolado/cordiforme con acabado más perfecto (fig. 8: 1; lám. III). Por otro lado, en todas las piezas retocadas y con fracturas, se observa el empleo de percutor elástico y las fracturas son posteriores al retoque al que afectan (lám. II: 1 y 2); no existe ningún plano de fractura que haya sido posteriormente modificado por retoque. Todas estas observaciones apoyan la posibilidad de que se trate de accidentes producidos en el curso de la talla y que las piezas hayan sido abandonadas a causa de estas roturas. Por otra parte resulta obvio que si la intención hubiera sido elaborar puntas foliáceas, el tamaño de muchos de estos soportes, después de la fractura, no hubiera impedido terminarlas.

\section{IV- CONCLUSIONES}

Las vicisitudes por las que ha pasado el estudio de Las Delicias son un fiel reflejo no solo de la investigación desarrollada en el Manzanares en los últimos 150 años, sino también de los avatares por los que ha pasado en general el Paleolítico español. Independientemente de esto, se trata de un yacimiento notable por ser una de las primeras excavaciones en yacimientos pleistocenos al aire libre de la Península, en la que se partió del reconocimiento de una estratigrafía y se alcanzó una interpretación funcional de la actividad humana.

Como hemos visto, las contribuciones de autores posteriores no han cuestionado la hipótesis principal de Obermaier y Wernert, para quienes Las Delicias constituyó un área de talla en la que se introdujo la materia prima desde una fuente de aprovisionamiento no inmediata, si bien este último aspecto creemos que no se ha subrayado debidamente, en especial en los últimos años.

Diferente suerte ha corrido la interpretación tipológica de la industria, adscrita primero a un Achelense final, y sucesivamente a distintas facies musterienses. Se hacía hincapié precisamente en los elementos foliáceos bifaciales, para nosotros definibles como bifaces, que han servido para justificar relaciones culturales o desplazamientos de grupos humanos de largo alcance. La Prehistoria se construía entonces en clave difusionista y no debe sorprendernos. Son modelos interpretativos superados y su discusión carece de vigencia.

Los intentos de revisión más recientes han olvidado examinar de nuevo la estratigrafía y, sobre todo, la situación morfoestratigráfica del yacimiento, limitándose a reconocer el aspecto Achelense final o Musteriense de la industria publicada y conservada en el MNCN (Freeman 1975).

La revisión que hemos efectuado en las páginas precedentes incide en todos estos aspectos y permite integrar mejor Las Delicias en el marco general del Paleolítico del Manzanares. La interpretación como taller vemos que encuentra sus principales puntos de apoyo en la descripción de la concentración de sílex (Obermaier y Wernert 1918: 16 ss.) y en la existencia de múltiples utensilios fracturados, aparentemente abandonados en el curso de su elaboración. La muestra instrumental conservada carece de otros elementos que refuercen esta hipótesis, que consideramos, no obstante, perfectamente viable pero pendiente de verificar.

La industria hay que reconocer que presenta elementos poco habituales en el contexto peninsular. Nos referimos a algunos bifaces planos, en especial a uno de ellos (fig. 8: 1), a partir del cual ha llegado a apuntarse para Las Delicias un horizonte Musteriense avanzado, del estilo de las industrias centroeuropeas con piezas foliáceas (Freund 1952), o incluso un solutrense (Baena et al. 2000: fig. 6, p.104) como el de El Sotillo. Ambas posibilidades nos parecen, con los datos disponibles, remotas. No sabemos que significación real pueden tener estas piezas en la industria de Las Delicias, y El Sotillo, al margen de cualquier consideración sobre la industria, ocupa una posición morfoestratigráfica muy concreta, a techo de la terraza de $+8 \mathrm{~m}$ 
del Manzanares, para la que está justificado suponer una cronología finipleistocena (Martínez de Merlo 1984). Desde una perspectiva cronológica los paralelos más inmediatos para Las Delicias deberían encontrarse en niveles más elevados, como por ejemplo en la terraza de $+12-15 \mathrm{~m}$, conservada en las inmediaciones, cerca de la desembocadura del arroyo de La Gavia, donde años atrás se excavó un importante yacimiento (Rus 1987: 39), o incluso en los niveles basales de la terraza de $+8 \mathrm{~m}$. Lamentablemente no es posible plantear comparaciones con industrias de otros puntos del Manzanares, pues si por el lado de Las Delicias se trata de una muestra seleccionada, del otro tampoco se conocen conjuntos homogéneos y bien definidos que puedan servir de referencia.

El posible taller excavado por Wernert y Obermaier en 1918 plantea en la actualidad no pocos interrogantes. Hace falta aún establecer en firme si se trata de un taller y cuales son sus características, desde las claves de su situación estratégica en relación con las materias primas hasta su cronología, las cadenas de transformación de la industria lítica o el papel del fuego, por mencionar alguna de las cuestiones que hemos tratado. Constituye, además, probablemente el único yacimiento al alcance de la investigación (delimitado, en contexto primario y bien localizado) en todo el ámbito del Manzanares. Creemos que su excavación es posible y que podría abrir, por fin, una nueva etapa en el estudio del Paleolítico de Madrid.

Agradecimientos: gracias a Begoña Sánchez Chillón y Javier Sánchez Almazán, del Departamento de Colecciones de Paleontología de Vertebrados del Museo Nacional de Ciencias Naturales, por las facilidades que nos dieron para estudiar la industria lítica. Agradecemos también al Dr. J. Baena sus comentarios sobre Las Delicias.

Dedicamos estas páginas, que pretenden impulsar el estudio del Paleolítico madrileño, a nuestro colega Enrique Vallespí, que entre otros muchos méritos, fue el promotor y es uno de los principales responsables del estudio del Paleolítico Inferior y Medio en las formaciones fluviales de la cuenca del Guadalquivir; en homenaje a la intensa labor de investigación, docencia y amistad que ha desarrollado en medio siglo de profesión.

\section{BIBLIOGRAFÍA}

AYARZAGÜENA SANZ, M. (1997): "La Sociedad Antropológica Española y el nacimiento de la ciencia prehistórica en España”, en G. Mora y M. Díaz-Andreu (eds.), La cristalización del pasado: génesis y desarrollo del marco institucional de la Arqueología en España: 295-301. Málaga. Servicio de publicaciones de la Universidad de Málaga

BAENA PREYSLER, J.; C. CONDE RUIZ; E. CARRIÓN SANTAFÉ y J. PASTOR MUÑOZ (2000): "Paleolítico y Epipaleolítico", en La Arqueología madrileña en el final del s. XX: desde la Prehistoria hasta el año 2000. Boletín de la Asociación Española de Amigos de la Arqueología 39-40: 81-104.

BORDES, F. (1961): "Typologie du Paléolithique ancien et moyen". Bordeaux. Imprimeries Delmas.

BRÉZILLON, M. (1977): "La dénomination des objets de pierre taillée". IV supplément à Gallia Préhistoire. Paris. Éditions du C.N.R.S.

CALVO SORANDO, J. P.; SAN JOSÉ LANCHA, M. A. y VEGAS MARTÍNEZ, R. (1989): Cartografía geológica del Terciario, geomorfología y Memoria correspondiente de la Hoja a E. 1:50.000 de Madrid (559). Madrid. Instituto Tecnológico GeoMinero de España

CARRERA, E. de y MARTÍN FLORES, A. (1997): "Las instituciones arqueológicas del Ayuntamiento de Madrid (1924-1972)", en G. Mora y M. Díaz-Andreu (eds.), La cristalización del pasado: génesis y desarrollo del marco institucional de la Arqueología en España: 581-592. Málaga. Servicio de publicaciones de la Universidad de Málaga. 
M. SANTONJA / A. PÉREZ-GONZÁLEZ / G. VEGA TOSCANO

DÍAZ-ANDREU, M. (1997): "Nación e internacionalización. La Arqueología en España en las tres primeras décadas del s. XX”, en G. Mora y M. Díaz-Andreu (eds.), La cristalización del pasado: génesis y desarrollo del marco institucional de la Arqueología en España: 403-416. Málaga. Servicio de publicaciones de la Universidad de Málaga.

ENAMORADO, J. (1984): "El Esbaikiense: sus implicaciones en la definición de una facies del Musteriense en el valle del Manzanares", Trabajos de Prehistoria 41: 293-303.

FREEMAN, L. G. (1975): "Acheulian Sites and Stratigraphy in Iberia and the Maghreb”, en K. W. Butzer y G. Ll. Isaac (eds), After the Australopithecines: 661-744. The Hague-Paris. Mouton Pub.

FREEMAN, L. G. (1991): "What mean these stone? Remarks on raw materials use in the Spanish Paleolithic", en A. Montet-White y S. Holen (eds.), Raw Material Economy Among Prehistoric Hunter-Gatherers: 73-125. Lawrence. University of Kansas Press.

FREUND, G. (1952): Die Blattspizen des Palaolithikums in Europa. Bonn. Quarter Bibliotek.

GONZÁLEZ ECHEGARAY, J. y FREEMAN, L. G. (1998): Le Paléolithique inférieur et moyen en Espagne. Grenoble. Éditions Jérôme Millon.

GOY, J.L.; PÉREZ-GONZÁLEZ, A. y ZAZO, C. 1(989): Cartografía geológica del Cuaternario, geomorfología y Memoria correspondiente de la Hoja a E. 1:50.000 de Madrid (559). Madrid: Instituto Tecnológico GeoMinero de España.

GROENEN, M. (1994): Pour une histoire de la Préhistoire: le Paléolithique. Jerôme Millon, Grenoble. HERNÁNDEZ PACHECO, E. (1928): Los cinco ríos principales de España y sus terrazas. Madrid. Trabajos del Museo Nacional de Ciencias Naturales. Serie Geológica, $\mathrm{n}^{\circ} 36$.

HERNÁNDEZPACHECO, E. (1959): Prehistoria del solar hispano. Madrid. Memorias de la Real Academia de Ciencias Exactas, Físicas y Naturales de Madrid, Serie Ciencias Naturales, t. 20.

JORDÁ CERDÁ, F. (1955): El Solutrense en España y sus problemas. Oviedo. Diputación Provincial de Asturias.

MAIER, J. (2000): "Historiografía de la Arqueología matritense", en La Arqueología madrileña en el final del s. XX: desde la Prehistoria hasta el año 2000. Boletín de la Asociación Española de Amigos de la Arqueología, 39-40: 41-66.

MARTÍNEZ DE MERLO, A. M. (1984): "El Paleolítico superior en el valle del Manzanares: el yacimiento de El Sotillo", Boletín del Museo Arqueológico Nacional, II (1): 47-68.

MOURE ROMANILLO, A. (1996): "Hugo Obermaier, la institucionalización de las investigaciones y la integración de los estudios de Prehistoria en la Universidad española", en A. Moure (ed.), "El Hombre Fósil" 80 años después: 17-50. Santander. Ediciones Universidad de Cantabria.

OBERMAIER, H. (1916): El Hombre Fósil. Madrid. Comisión de Investigaciones Paleontológicas y Prehistóricas, Mem. no 9 (2 $2^{a}$ edición aumentada: 1925).

OBERMAIER, H. y PÉREZ DE BARRADAS, J. (1924): "Las diferentes facies del Musteriense español y especialmente de los yacimientos madrileños", Revista de la Biblioteca, Archivo y Museo del Ayuntamiento de Madrid, Año 1, $\mathrm{n}^{\mathrm{o}}$ 2: 143-177.

OBERMAIER, H. y WERNERT, P. (1917): Yacimiento prehistórico de Las Carolinas (Madrid). Madrid. Comisión de Investigaciones Paleontológicas y Prehistóricas. Memoria $\mathrm{n}^{\circ} 16$.

OBERMAIER, H. y WERNERT, P. (1918): Yacimiento paleolítico de Las Delicias (Madrid). Madrid. Memorias de la Real Sociedad Española de Historia Natural. Museo de Ciencias Naturales.

PASAMAR, G. y PEIRO, I. (1991): "Los orígenes de la profesionalización historiográfica española sobre Prehistoria y Antigüedad (tradiciones decimonónicas e influencias europeas)", en J. Arce y R. Olmos (coords): Historiografía de la Arqueología y de la $H^{a}$ Antigua en España (siglos XVIII-XX): 73-77, $\mathrm{M}^{\circ}$ de Cultura, Madrid. 
PAZ GRAELLS, M. de la (1897): Fauna mastológica ibérica. Madrid. Real Academia de Ciencias Exactas, Físicas y Naturales.

PÉREZ DE BARRADAS, J. (1923): "Las terrazas cuaternarias del valle del Manzanares”, Ibérica XX, $n^{\circ}$ 486: 42-44.

PÉREZ DE BARRADAS, J. (1924): "Introducción al estudio de la prehistoria madrileña", Revista de la Biblioteca, Archivo y Museo del Ayuntamiento de Madrid, Año 1, no 1: 13-35.

PÉREZDEBARRADAS, J. (1926): Estudios sobre el terreno cuaternario del valle del Manzanares (Madrid). Madrid. Imprenta Municipal.

PÉREZ DE BARRADAS, J. (1929): “Los yacimientos prehistóricos de los alrededores de Madrid”, Boletín Geológico y Minero LI: 153-322.

PÉREZ DE BARRADAS, J. (1932): Recensión de "Le Clactonien et sa place dans la chronologie...”, de H. Breuil, Anuario de Prehistoria Madrileña II-III: 212-213.

PÉREZ DE BARRADAS, J. (1934): "Influences africaines dans le Paleolithique de Madrid", Anuario de Prehistoria Madrileña II-III: 3-11.

PÉREZ DE BARRADAS, J. (1934 a): "El Acheulense del valle del Manzanares (Madrid)", Anuario del Cuerpo Facultativo de Archiveros, Bibliotecarios y Arqueólogos I: 1-18.

PÉREZ DE BARRADAS, J. (1934 b): “Los problemas del Paleolítico Superior madrileño", Investigación y Progreso VIII, 9: 249-254.

PÉREZDE BARRADAS, J. (1936): "Nuevos estudios de Prehistoria madrileña: la colección Bento”, Anuario de Prehistoria Madrileña IV-V (1933-1936): 1-90.

PÉREZ DE BARRADAS, J. (1941): “Nuevas investigaciones sobre el yacimiento de San Isidro (Madrid)”, Archivo Español de Arqueología 43: 277-303.

PÉREZ DE BARRADAS, J. y WERNERT, P. (1919): "El Almendro. Nueva estación cuaternaria en el valle del Manzanares (Villaverde, Madrid)", Boletín de la Real Soc. Española de Excursiones XXVII: 238-269.

PÉREZ-GONZÁLEZ, A. (1971): "Estudio de los procesos de hundimiento en el valle del río Jarama y sus terrazas (nota preliminar)", Estudios Geológicos XXXVII: 317-324.

PÉREZ-GONZÁLEZ, A. (1980): "Geología y estratigrafía de los yacimientos de Aridos en la llanura aluvial de Arganda (Madrid)", en Ocupaciones achelenses en el valle del Jarama: 49-61. Madrid. Diputación Provincial.

PRADO, C. de (1864): Descripción física y geológica de la provincia de Madrid. Madrid. Junta General de Estadística. (Reedición: (1975) Madrid. Colegio de Ingenieros de Caminos Canales y Puertos).

PRIEGO, C. (1982): "José Pérez de Barradas: in memoriam", Estudios de Prehistoria y Arqueología Madrileñas 1: 11-18.

QUERO CASTRO, S. (1994): "Excavación del elefante de Orcasitas (Madrid)”, Estudios de Prehistoria y Arqueología Madrileñas 9: 11-16.

QUERO CASTRO, S. (1996): "Cuarenta años de historia del Instituto Arqueológico Municipal", Estudios de Prehistoria y Arqueología Madrileñas v. 10: 193-200.

RÉVILLION, S. (1994): Les industries laminaires du Paléolithique moyen en Europe septentrionale. Lille: Centre d'Études et de Recherches Préhistoriques.

ROYO GÓMEZ, J.; MENÉNDEZ PUGET, L. y ABBAD, M. (1929): Memoria explicativa de la Hoja Geológica a E. 1:50.000 n ${ }^{\circ}$ 559. Madrid. Madrid. Instituto Geológico y Minero.

RUS, I. (1987): "El Paleolítico”, en 130 años de Arqueología madrileña: 22-43. Madrid. Comunidad de Madrid.

SANTA OLALLA, J. (1941): "El Conde de la Vega del Sella. Necrológica”, Atlantis XVI, III-IV: 402-405. 
SANTONJA, M.; PÉREZ-GONZÁLEZ, A.; VEGA TOSCANO, G. y RUS, I. (2001): "Elephants and stone artifacts in the Middle Pleistocene terraces of the Manzanares river (Madrid, Spain)", The World of Elephants. Proceedings of the I Int. Congress: 597-601. Roma.

SANTONJA, M. y QUEROL, A. (1980): "Características de la ocupación humana en los suelos achelenses de la terraza de Aridos (Arganda, Madrid)”, en Ocupaciones Achelenses en el valle del Jarama: 321-336. Madrid. Diputación Provincial.

SEQUEIROS, L. (1996): “Geología y política: Casiano de Prado y Vallo (1797-1866)”, Tierra y Tecnología $n^{\circ} 14-15: 51-52$.

SESÉ, C. y SOTO, E. (2000): "Vertebrados del Pleistoceno de Madrid", en J. Morales (coord.), Patrimonio Paleontológico de la Comunidad de Madrid:216-243. Madrid. Consejería de Educación de la Comunidad de Madrid.

TIXIER, J. (1956): "Le hachereau dans l'Acheuléen nord-africain. Notes typologiques”, Cogrès Prehist. Fr. XV session: 914 -923. Poitiers-Angoulême.

WERNERT, P. y PÉREZ DE BARRADAS, J. (1925): "El yacimiento paleolítico de San Isidro. Estudio bibliográfico-crítico", Revista de la Biblioteca, Archivo y Museo del Ayuntamiento de Madrid 5: 31-68.

WERNERT, P. y PÉREZ DE BARRADAS, J. (1930-1932): “El yacimiento paleolítico de El Sotillo", Anuario de Prehistoria Madrileña I: 37-95; II-III: 13-60. 

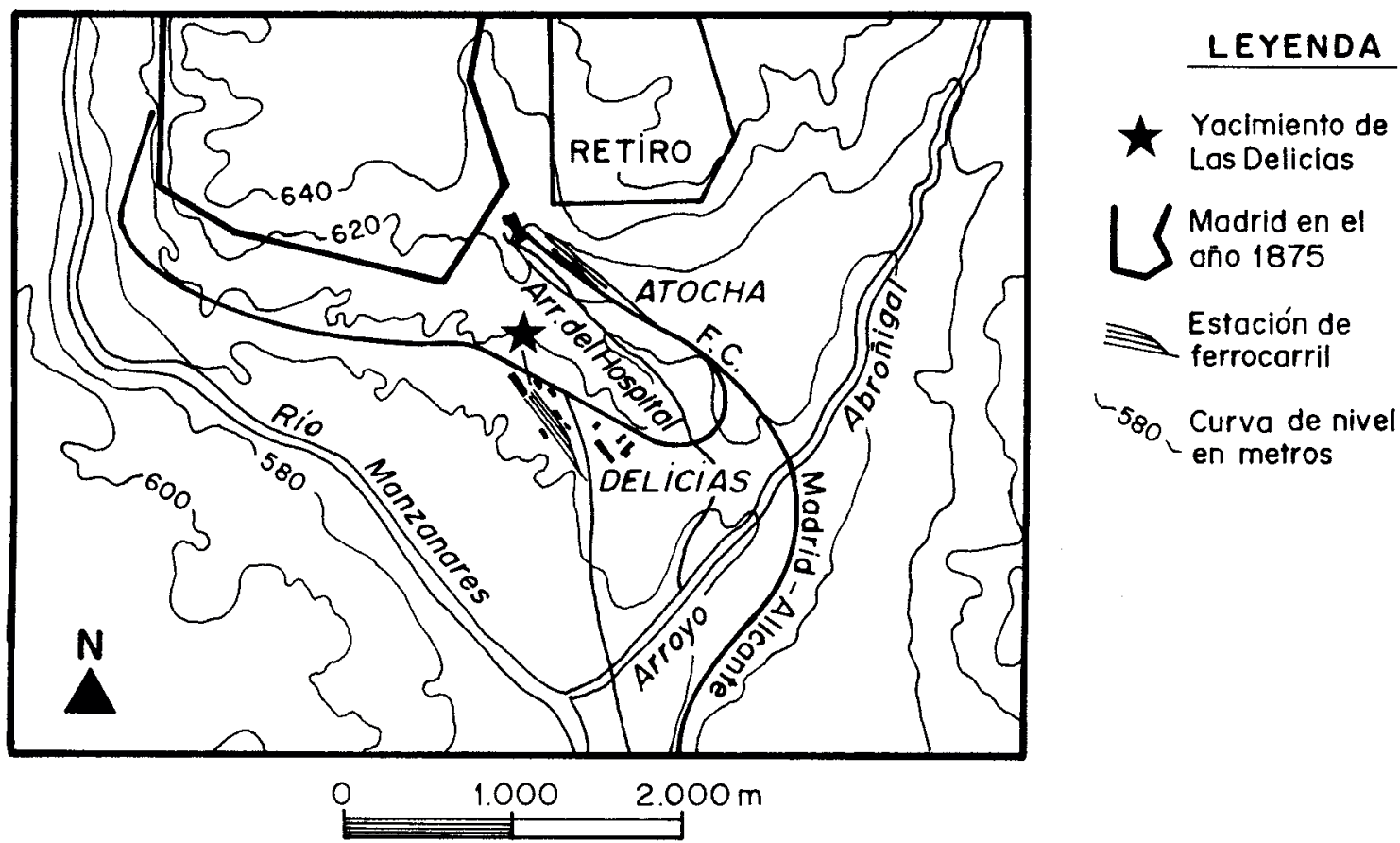

Figura 1: Mapa de situación general del yacimiento de Las Delicias. La topografía corresponde al Mapa Topográfico Nacional del año 1875. 

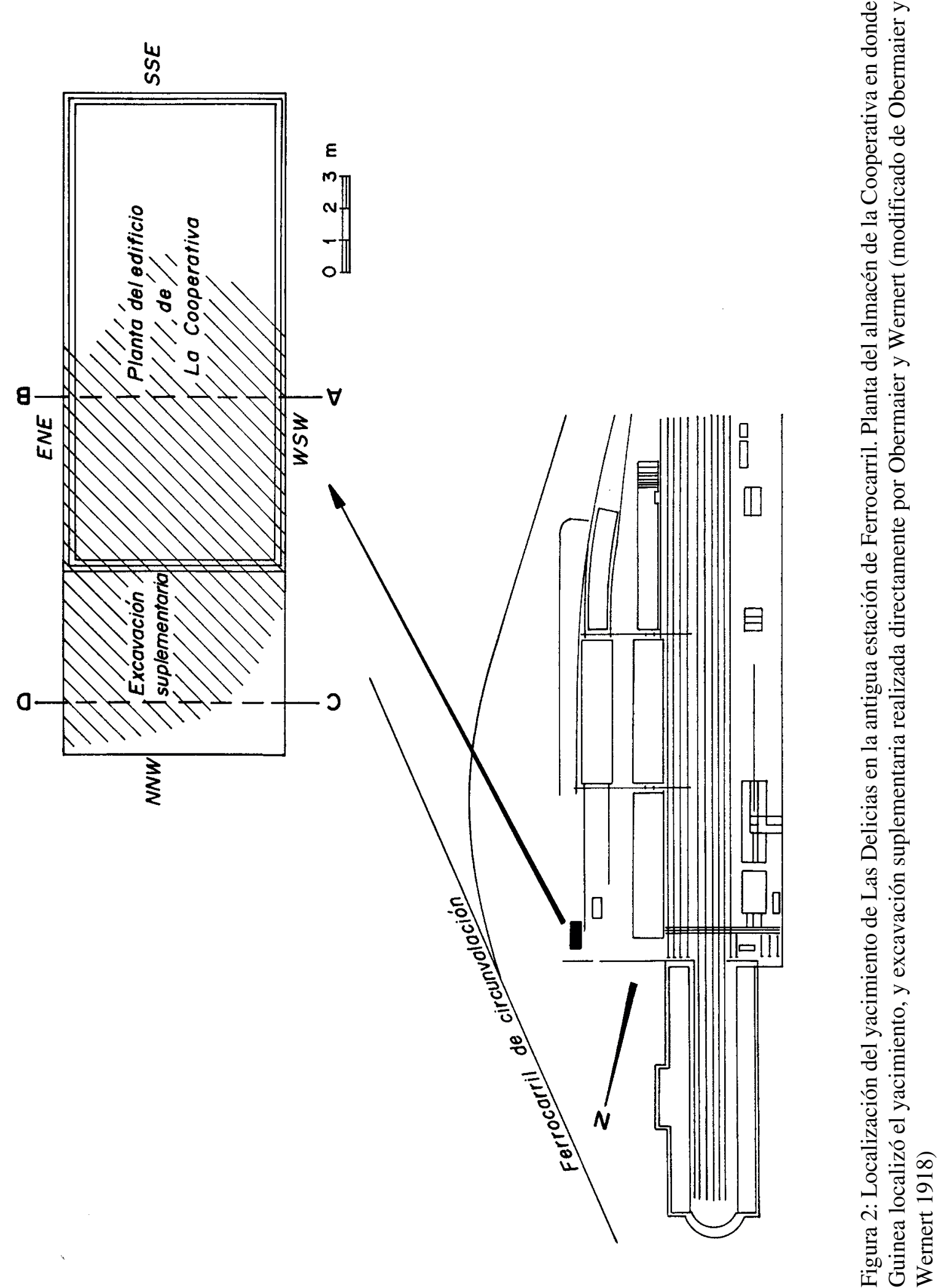

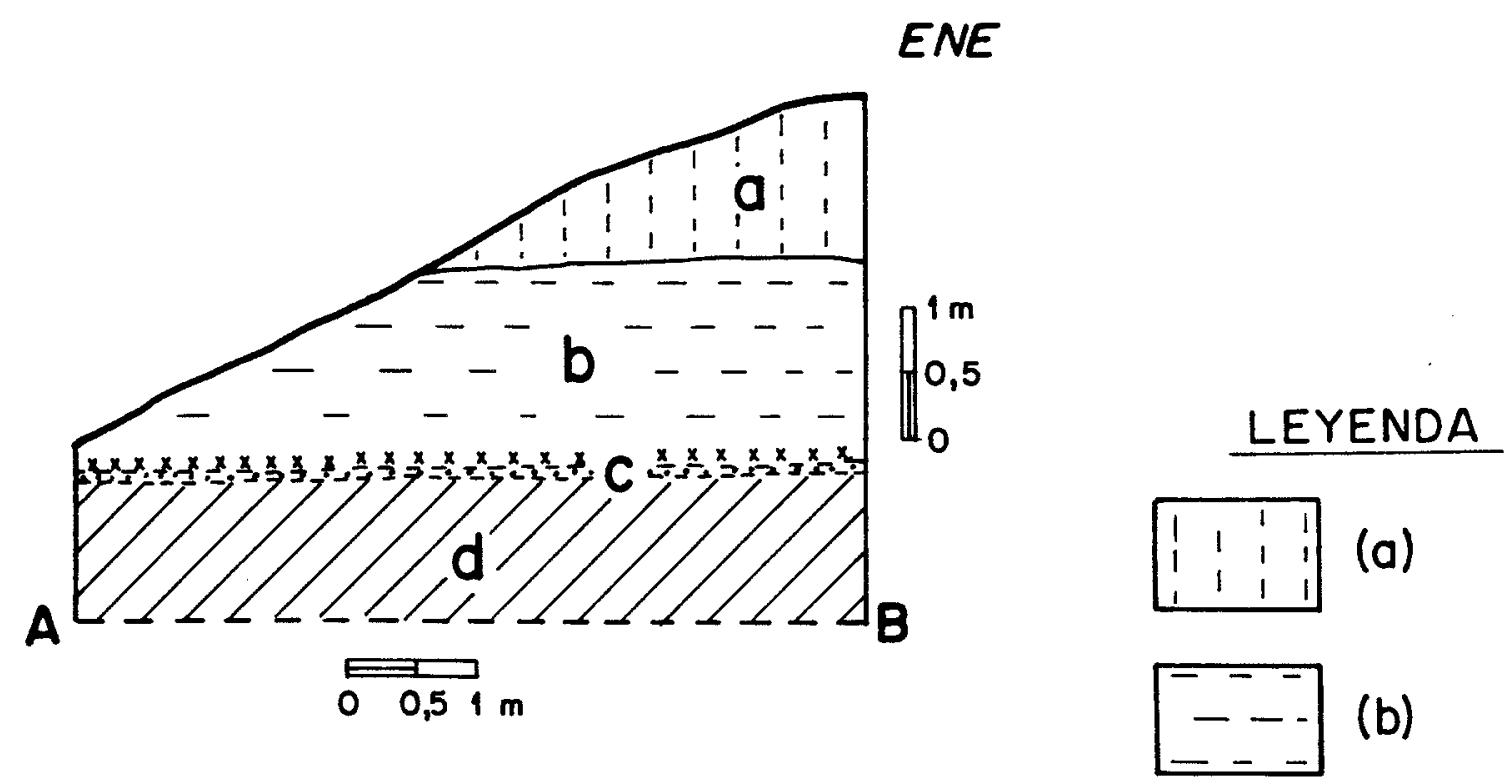

(b)

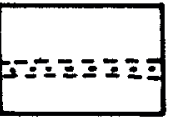

(c)

ENE

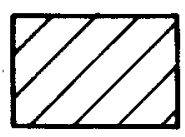

(d)
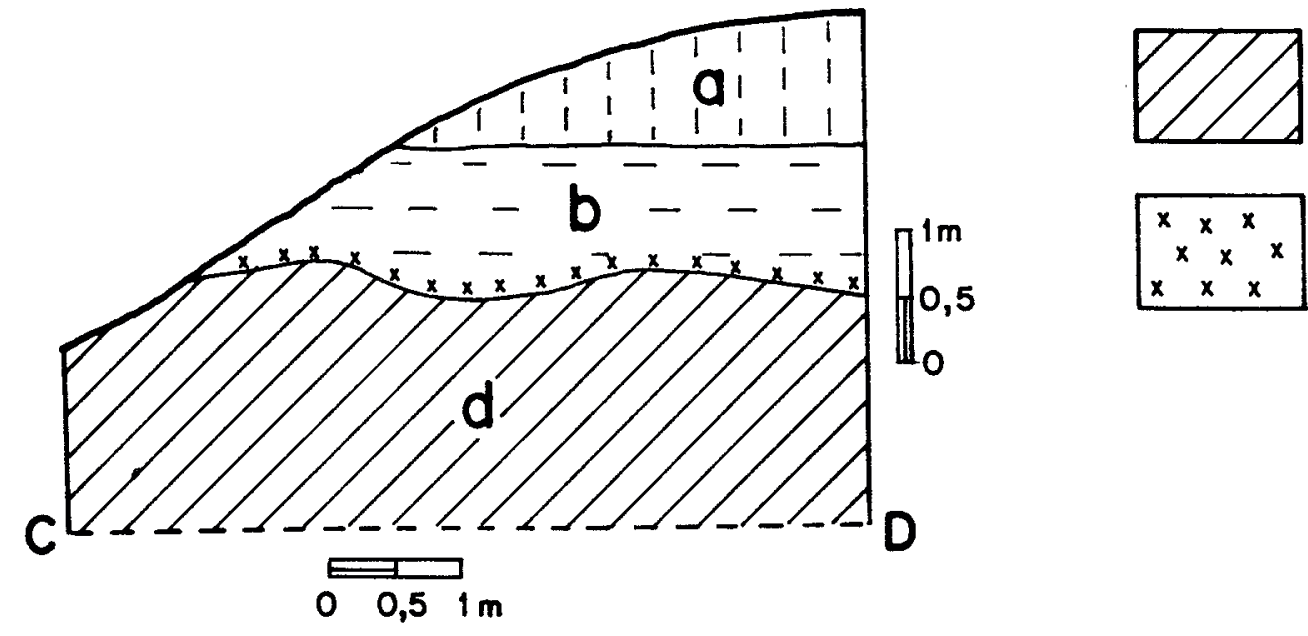

Figura 3: Estratigrafía de Las Delicias (modificada de Obermaier y Wernert 1918). Leyenda: (a): tierra vegetal con arcilla. Espesor máximo 1,20 m (b): margas arcillosas detríticas con nódulos y concreciones de carbonato. Espesor máximo 1,50 m (c): horizonte arenoso. (d) sustrato terciario. (x): nivel con concentración de sílex tallados 

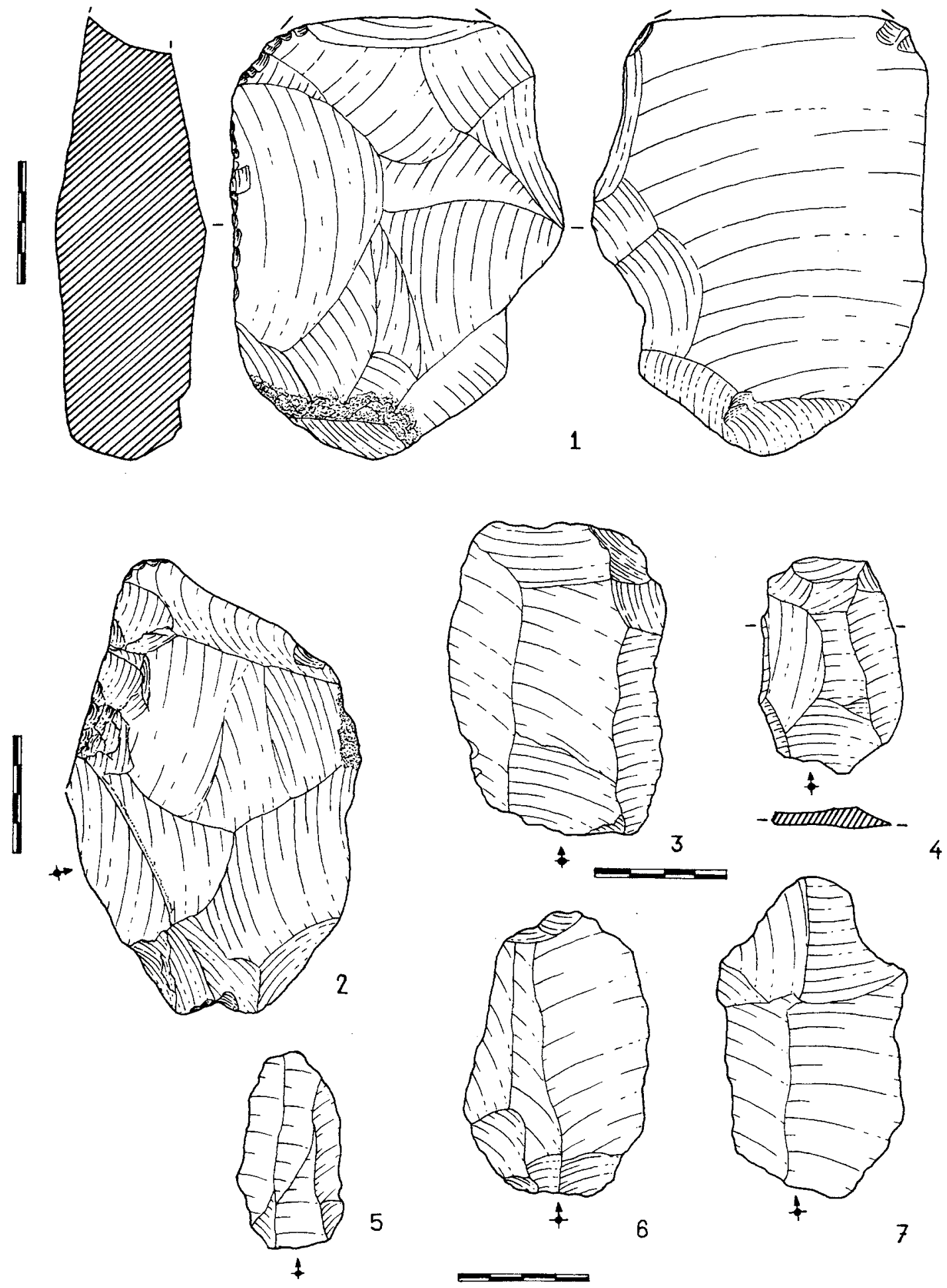

Figura 4: 1: hendedor de tipo III, con fractura antigua distal; 2: cuchillo de dorso atípico sílex tabular. 3-7: lascas levallois. 

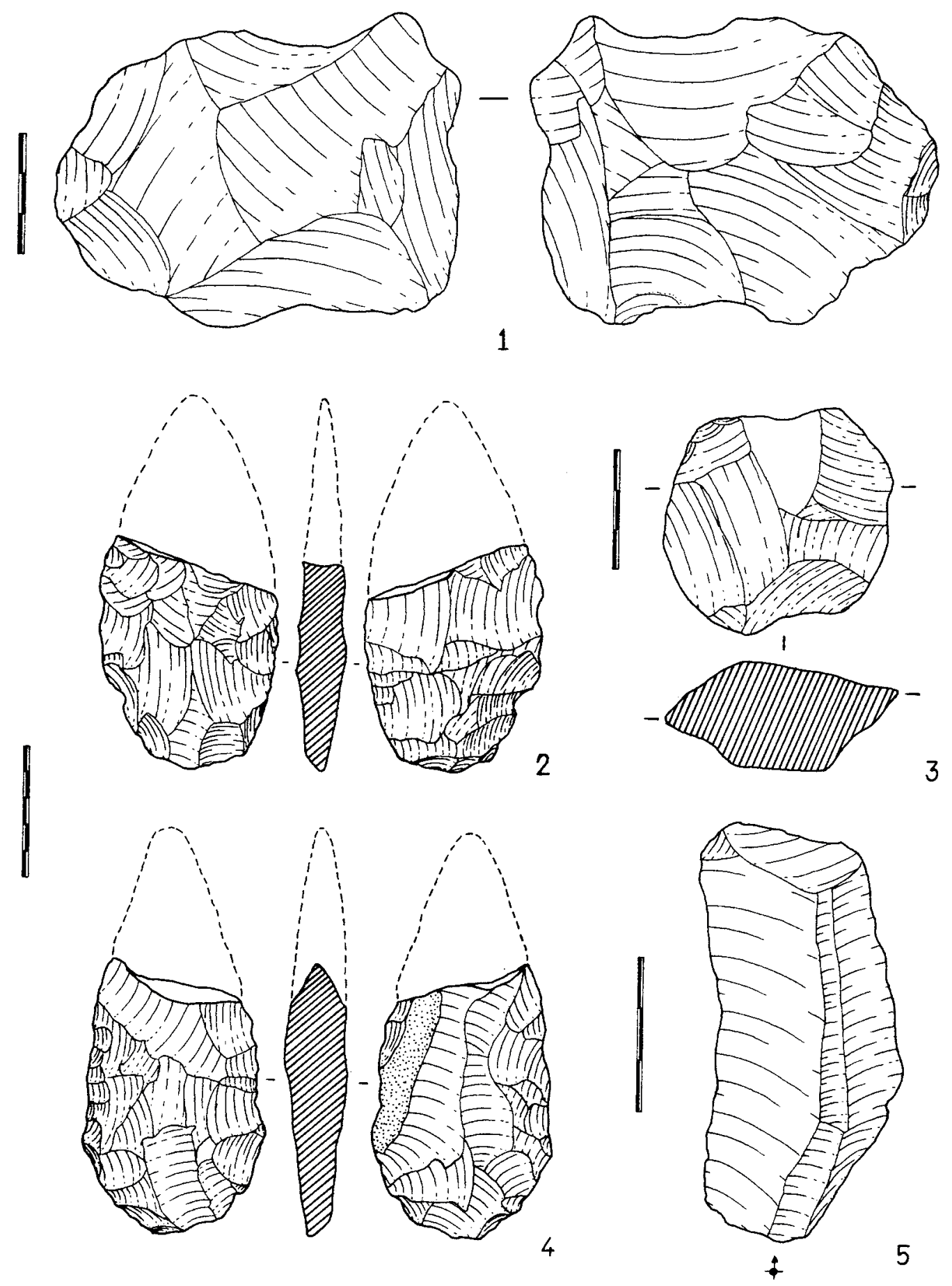

Figura 5: 1: núcleo discoide no levallois. 2: bifaz fracturado, posiblemente cordiforme (no conservado; según Obermaier y Wernert). 3: núcleo levallois recurrente, con explotación centrípeta y extracción posterior; presenta un desprendimiento de posible origen térmico. 4: bifaz fracturado, posiblemente lanceolado (no conservado; según Obermaier y Wernert). 5: lámina levallois. 

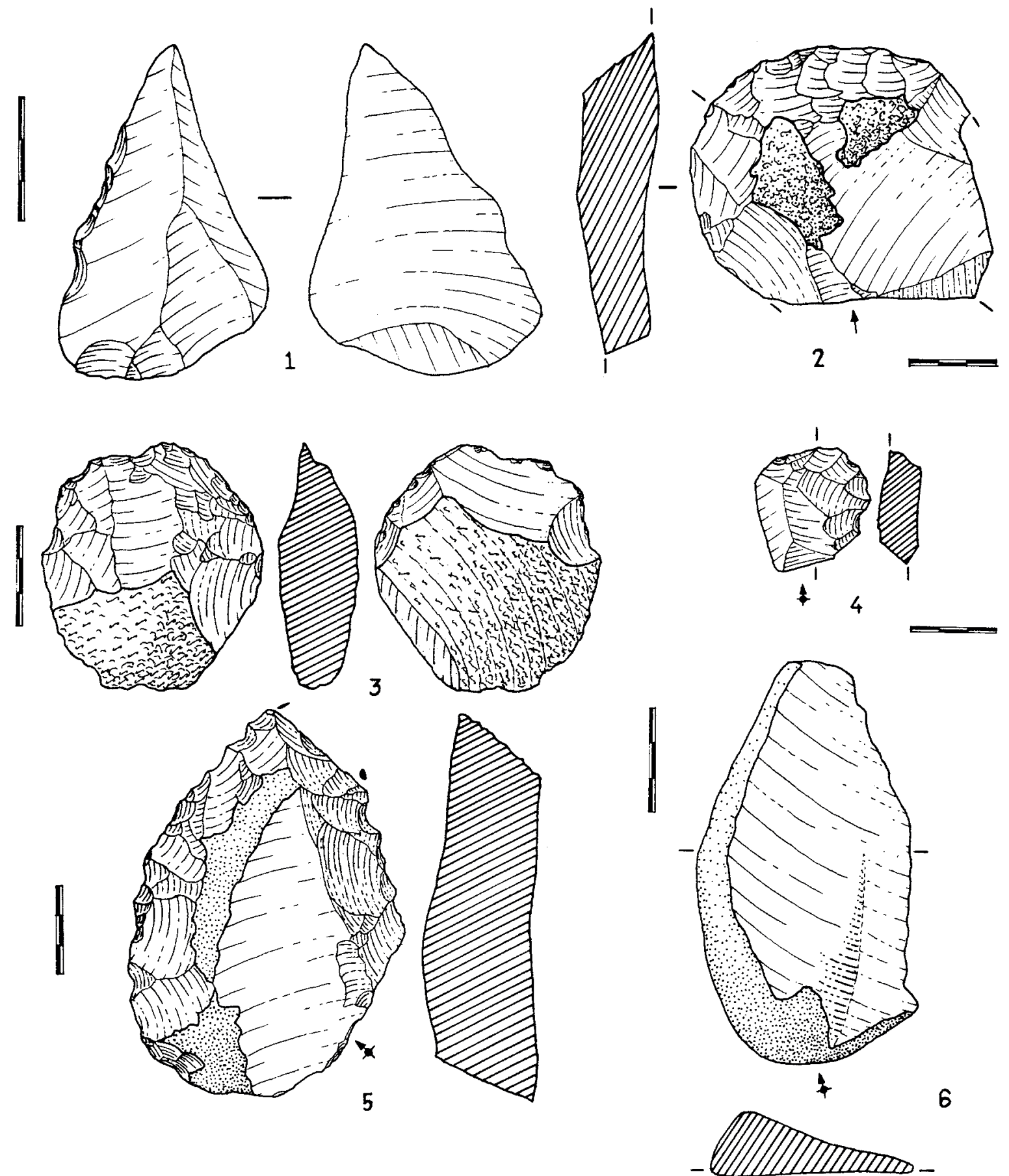

Figura 6: 1: punta levallois retocada; 2: raedera convexa transversal; presenta fracturas antiguas. 3: raedera convexa adelgazada; sobre lasca con espesa capa de subcórtex. 4: raspador espeso. 5: raedera convergente desviada, con fractura distal. 6: cuchillo de dorso natural, cuarcita. 

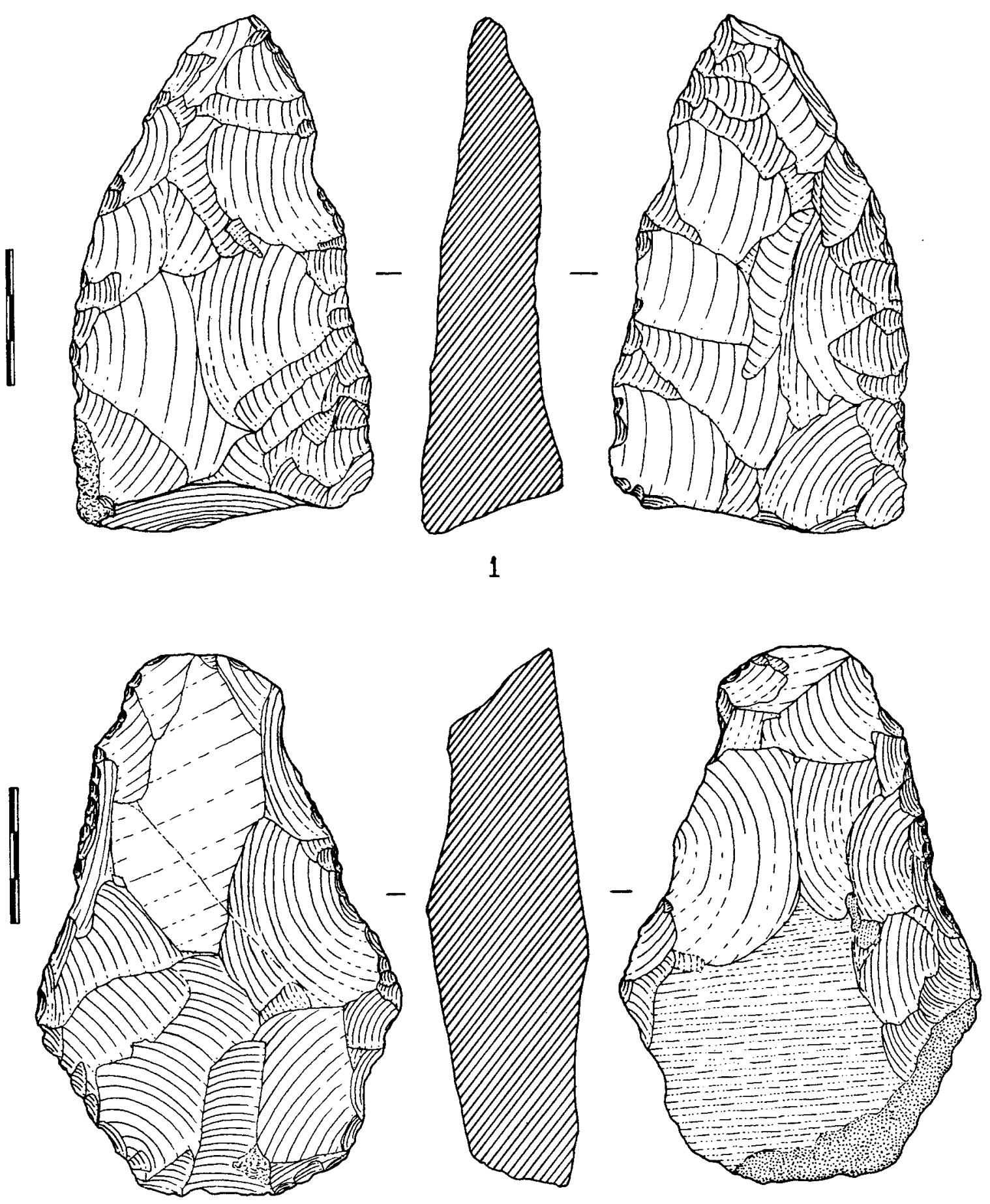

Figura 7: 1: bifaz subtriangular; base formada por el negativo de una extracción ortogonal al plano principal. 2: bifaz amigdaloide, sílex tabular. 

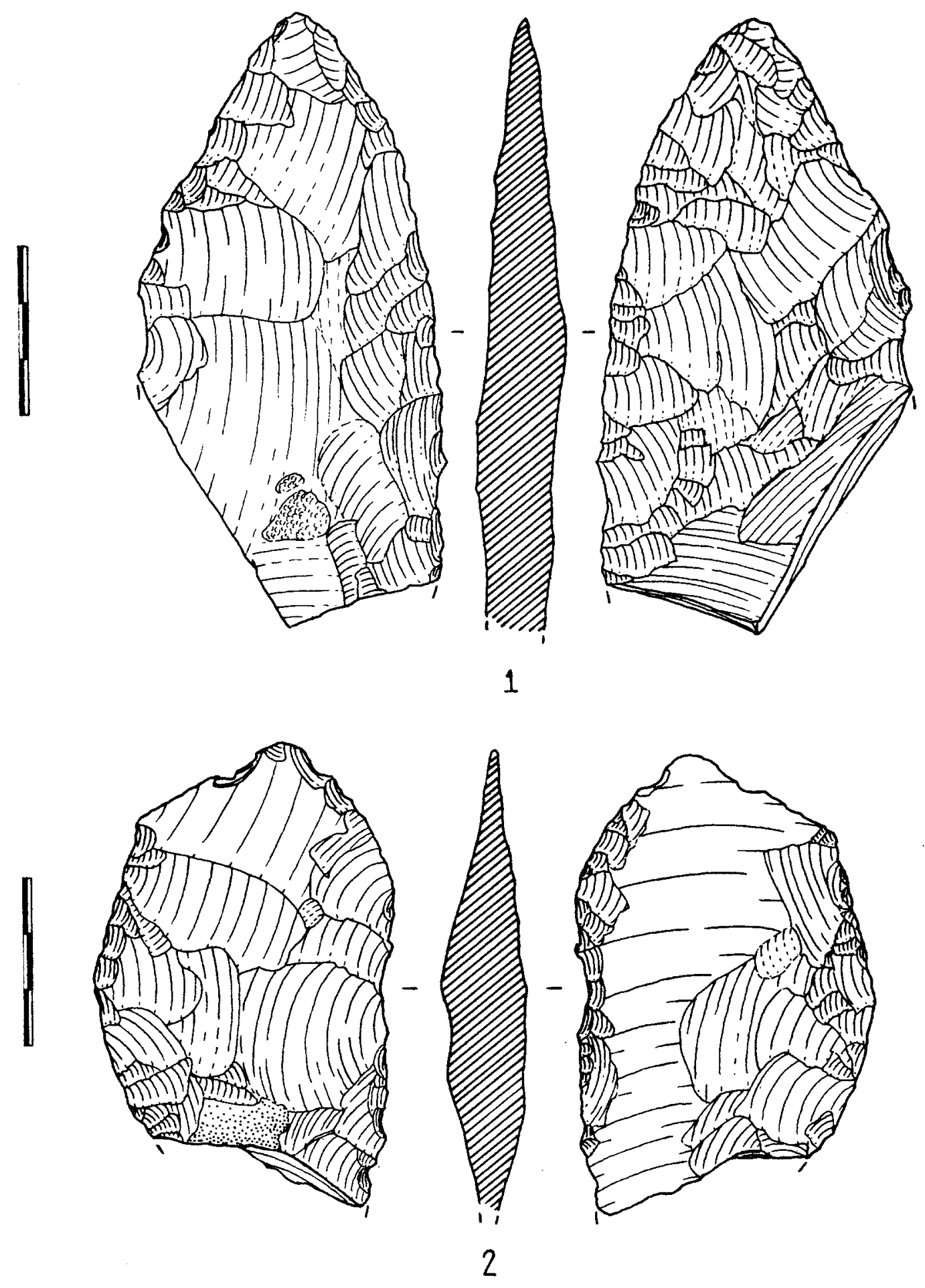

Figura 8: 1: parte distal de un bifaz lanceolado o cordiforme, con talla muy cuidada y doble fractura en la zona basal. 2: bifaz inacabado, sobre lasca, contorno ovalar. 

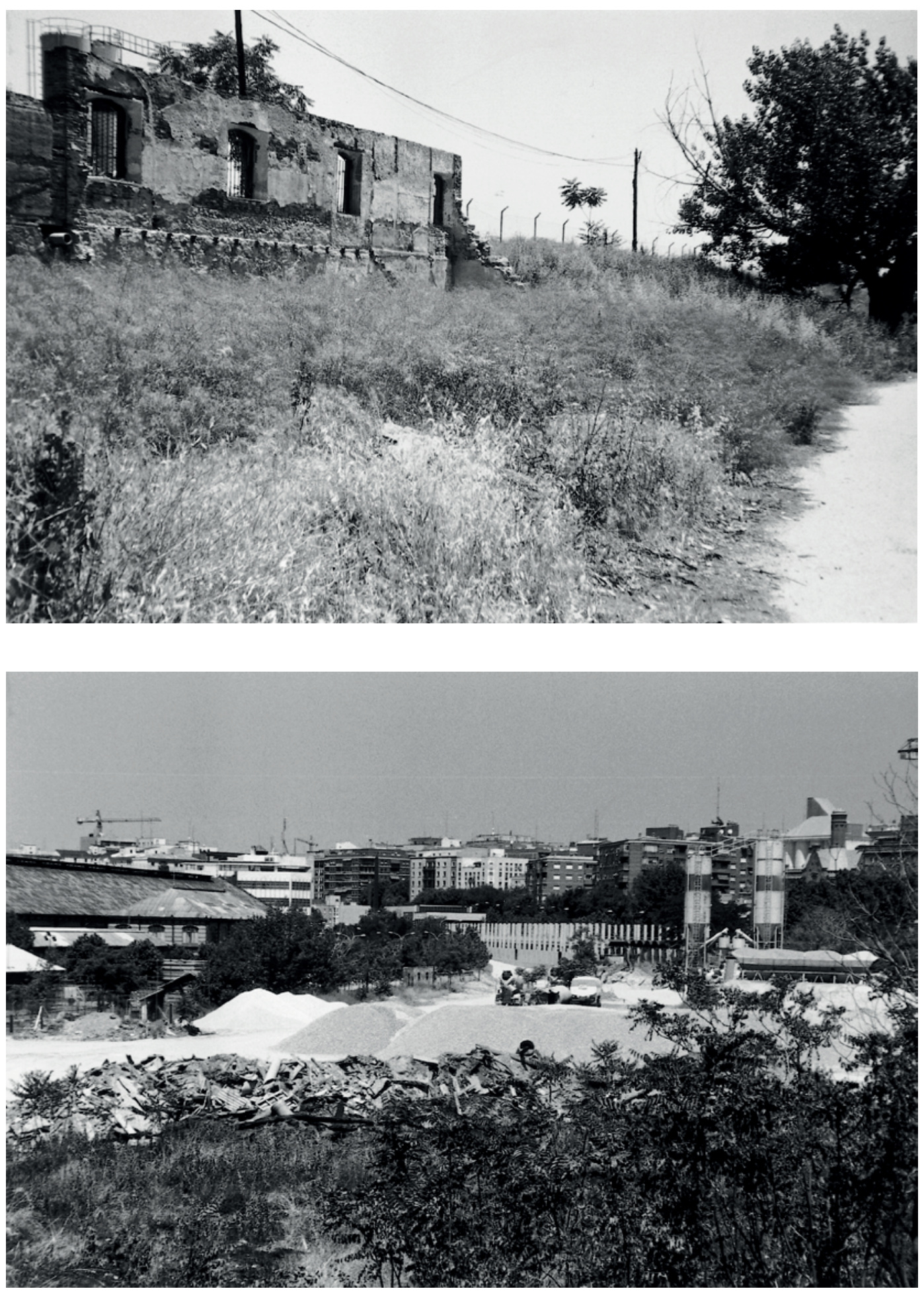

Lámina I: Yacimiento de Las Delicias. Estado actual. 1: ruinas del almacén de La Cooperativa. 2: los restos del edificio de La Cooperativa se encuentran en el centro de la imagen, entre los árboles; bajo la explanada a la derecha se conserva yacimiento. 

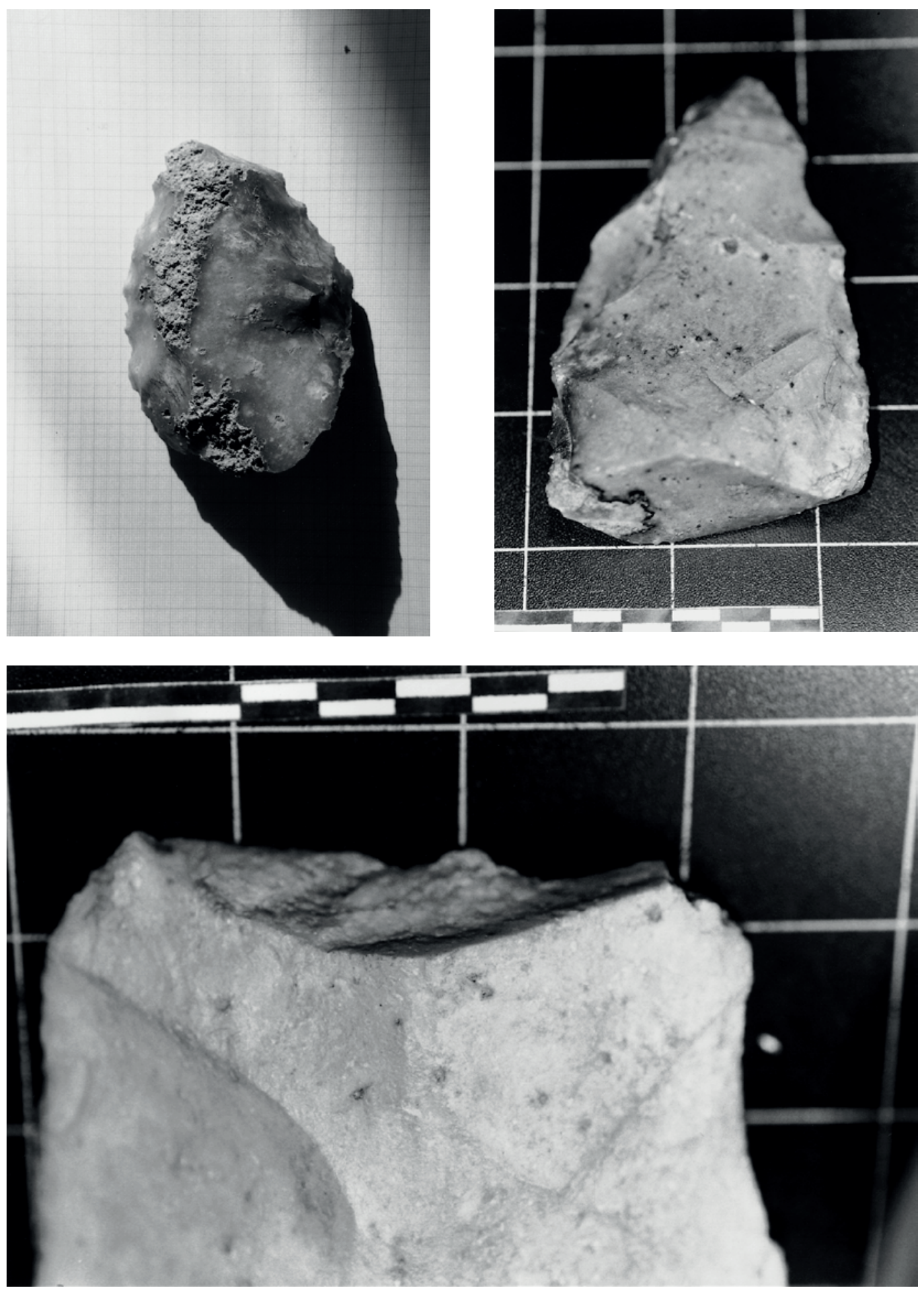

Lámina II:1: raedera desviada, presenta una fractura distal posterior al retoque. 2: aspecto de la base del bifaz subtriangular; puede observarse un contrabulbo central neto. Obsérvese el aspecto redondeado de las aristas. 3: fractura distal del hendedor, que afecta al retoque lateral. 

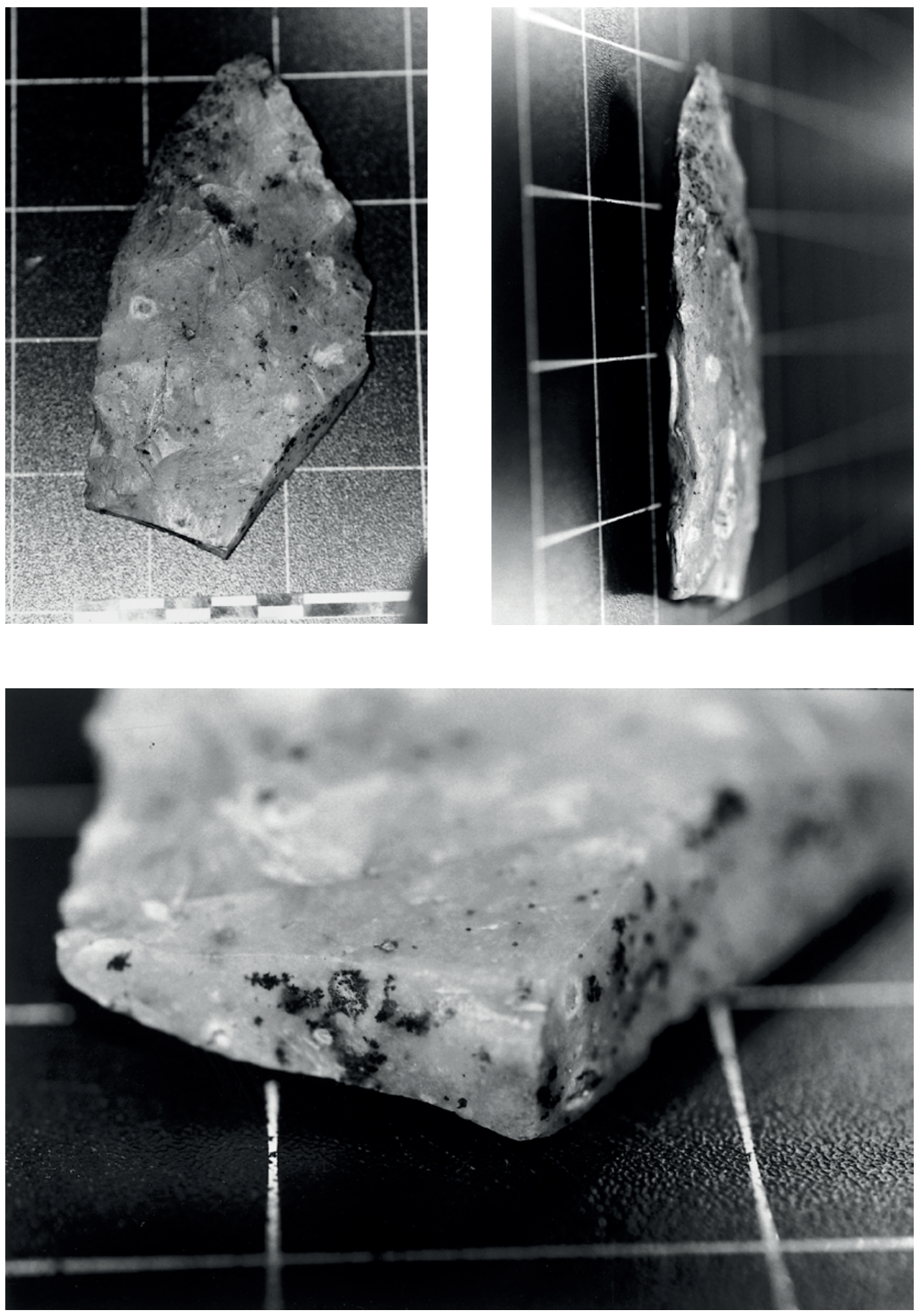

Lámina III: bifaz lanceolado o cordiforme fragmentado: contorno general (1), vista lateral oblicua (2) y detalle de las fracturas basales (3), obsérvese el aspecto redondeado de las aristas.

ISSN: 1133-4525 ISSN-e: 2255-3924 